\title{
Spectrum Conversion Factor and its Application for Ground Motion Simulation
}

\author{
Kenichi NAGAO ${ }^{1}$ and Jun KANDA ${ }^{2}$ \\ ${ }^{1}$ Structural Engineer, Daiwa House Industry, \\ Osaka, Japan, nagaok@daiwahouse.jp \\ ${ }^{2}$ Professor, Dept. of Architecture, Nihon University, \\ Tokyo, Japan, kanda@arch.cst.nihon-u.ac.jp
}

\begin{abstract}
Concept of the Spectrum Conversion Factor (SCF), the ratio of the equivalent velocity (total energy input to structures) and spectral velocity (peak response velocity), is introduced and relationships between the standard deviation of phase difference $(\sigma)$ and SCF are investigated. With damping, $\sigma$-SCF relations always have a positive slope, and the slopes are steeper in higher frequency band or higher damping ratio cases. In the final part of this study, three artificial ground motions compatible to design response spectra and the expected design energy spectra were demonstrated.
\end{abstract}

Key Words: Spectrum conversion factor, phase difference, response spectrum, energy spectrum

\section{INTRODUCTION}

When determining a structure's horizontal, vertical, and torsional capacities, estimation of the possible peak stresses and responses to loadings is of great concern. The concept of the response spectrum, initiated by Biot (1933) and established by Housner (1941), enables to obtain the peak displacement, velocity, and acceleration responses for elastic-linear Single-Degree-of-Freedom (SDF) systems with the natural frequency, $f_{n}$, and damping ratio, $\zeta$. On the other hand, Housner (1956) assumed that the input energy causing the plastic deformation of structures (the plastic deformation energy, $E_{D}$ ) could be estimated directly from the elastic velocity response spectrum. He verified the assumption using a few structural damage examples (Housner 1959). Kato and Akiyama (1975) showed that the total amount of energy $(E)$ to structures depends mainly on the natural period $T_{n}$ and total mass $m$, not on the damping ratio and restoring force characteristics.

More than 10 years later, Akiyama (1985) established the concept of the energy spectrum (the $V_{E}$ spectrum). The energy spectrum is a plot of relationship between the natural frequency $f_{n}$ or natural period $T_{n}$ and the equivalent velocity, $V_{E}$, a quantity obtained from square root of the total energy divided by the total mass. The energy spectrum gives general idea about the amount of energy input to structures. Akiyama (1985) also proposed the design energy spectra represented by bilinear models based on the El Centro and Taft records. See Fig. 1, for the El Centro case. Note that these spectra are for the engineering bedrocks, where the shear wave velocity is more than $400 \mathrm{~m} / \mathrm{sec}$ and with $\zeta=10 \%$. This energy concept has been adopted in Japan's building code. The spectra in the code have the similar shape as Fig. 1. 


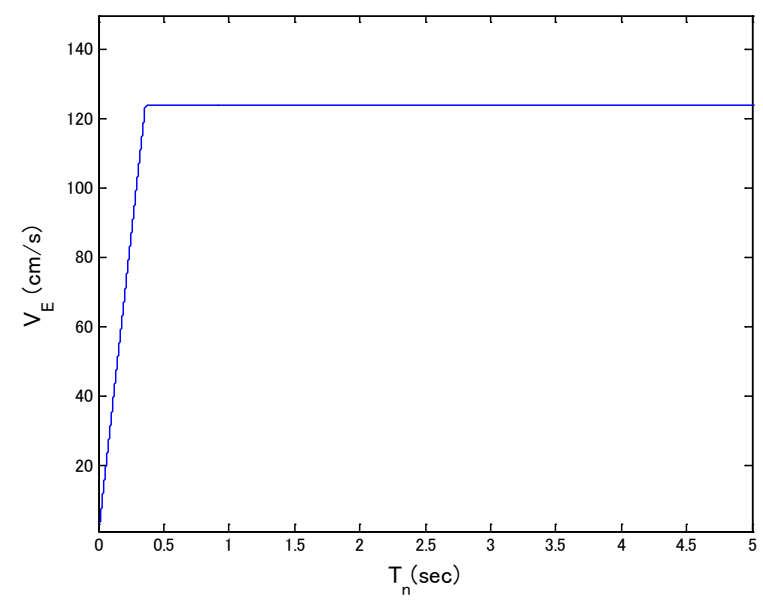

Fig. 1 The design energy spectrum determined using the El Centro ground motion

However, influences from the duration of strong motion also cannot be negligible when estimating elastic and plastic responses. Noting this idea generally corresponds with considering "how rapidly" the energy is put into structures. It can be assumed that with the same amounts of total energy, shorter-duration ground motions will have more energy around the peak location in the time domain, causing higher peak response quantities.

Hence one could assume that the peak responses would be related to the duration of strong motion. And because the response spectra are of the peak response quantities, it is reasonable to investigate the relationship between the response spectrum (peak), especially the velocity response spectrum, and the energy spectrum (total energy) to estimate the influences from the duration of strong motion. To fulfill the purpose, Spectrum Conversion Factor, denoted as SCF, was defined as follows:

$$
S C F(f . b ., \zeta)=\frac{V_{E}(f \cdot b ., \zeta)}{S_{V}(f . b ., \zeta)}
$$

where f.b. represents the oscillator frequency band and $\zeta$ is the damping ratio. The SCFs are calculated in the following ten frequency bands: $0.1-1.0 \mathrm{~Hz}, 1.0-2.0 \mathrm{~Hz}, 2.0-3.0 \mathrm{~Hz}, 3.0-4.0 \mathrm{~Hz}, 4.0-5.0$ $\mathrm{Hz}, 5.0-6.0 \mathrm{~Hz}, 6.0-7.0 \mathrm{~Hz}, 7.0-8.0 \mathrm{~Hz}, 8.0-9.0 \mathrm{~Hz}$, and $9.0-10.0 \mathrm{~Hz}$.

Three previous researches regarding the $S_{V}-V_{E}$ ratio were found. (Note that those researches did not use the term $S C F$, but used $S_{v}-V_{E}$ ratio.)

Akiyama and Kitamura (2006) assumed that the ground motions with long strong motion duration could be expressed as a repetition of a single elemental earthquake with the number of repetition, $f$, and obtained a simple equation representing the relationship between the $f$ value and $S_{v}-V_{E}$ ratio. In their research, the El Centro ground motion was defined as the elemental earthquake. Although their methodology was unique, physical meaning of $f$ value was not clearly stated: explanations that the El Centro motion was representative among ground motions would be necessary. Further, the dependence of $S_{v}-V_{E}$ ratio on the frequency band was not discussed. As Akiyama (1999) and Nagao and Kanda (2013) pointed out, the effect of the damping is not identical in all frequencies.

On the other hand, Miyake (2006) defined the numbers of loading cycles $N_{o}$ as $T_{d} / T_{n}$, where $T_{d}$ is the same as $D_{1-99}$ and $T_{n}$ is the natural period. Developed $N_{o}-S_{v}-V_{E}$-ratio relationships have a high correlation, indicating that the strong motion duration would be the key to explain the ratio. In their regression equation, the damping adjustment factor, $F_{h}$, defined as the square root of $\zeta_{0} / \zeta$, where $\zeta_{0}$ is 0.10 , was used. According to Nagao and Kanda (2013), this factor is influenced not only by $\zeta$ but also by frequency band and duration of strong motion.

The most recent research for $S_{V}-V_{E}$ ratio would be Okano et al. (2009). They derived a theoretical $S_{V}-V_{E}$ ratio using a relationship between the power spectrum and response spectrum for white noise. They compared the theoretical $S_{v}-V_{E}$ ratios with actual $S_{v}-V_{E}$ ratios computed from 33 natural ground 
motion records.

So far, possible influences on the $S_{v}-V_{E}$ ratio from seismic characteristics such as magnitude and rupture type have not been discussed. In this research, the relationships between the SCFs and $\sigma$, the standard deviation of phase difference, in ten frequency bands and with nine damping ratios are investigated. Generally the $\sigma$ can be regarded as the strong motion duration. Ground motion records of seventeen earthquake events were analyzed. Hence this research takes into account the effects from the damping ratio, strong motion duration, seismic characteristics, and frequency band on the SCFs. Using the $\sigma$ also enables to define the phase characteristics, which is advantageous in simulating artificial design ground motions by the inverse FFT. In the final part, three artificial ground motions compatible to design response spectra and expected design energy spectra are demonstrated.

\section{DEFINITION OF PHASE DIFFERENCE}

Ohsaki (1979) defined the phase difference as follows:

$$
\begin{gathered}
\Delta \phi_{\mathrm{k}}=\phi_{\mathrm{k}+1}-\phi_{\mathrm{k}} \quad(k=1,2, \ldots N / 2-2) \\
\phi_{\mathrm{k}}=\tan ^{-1} \frac{-B_{k}}{A_{k}} \\
A_{k}=\frac{2}{N} \sum_{j=0}^{N-1} \ddot{y}_{j} \cos \frac{2 \pi k j}{N} \\
B_{k}=\frac{2}{N} \sum_{j=0}^{N-1} \ddot{y}_{j} \sin \frac{2 \pi k j}{N}
\end{gathered}
$$

where $\Delta \phi_{k}$ is the $k$ th phase difference in radian and $\phi_{k}$ is the $k$ th phase angle in radian.

The standard deviation of phase difference, $\sigma$, is defined as follows:

$$
\sigma=\sqrt{\frac{1}{N} \sum_{\mathrm{i}=1}^{N}\left(\Delta \phi_{\mathrm{i}}-\mu\right)^{2}}
$$

where $\mu$, the mean value of phase difference, is defined by Eq. (4).

$$
\mu=\frac{1}{N} \sum_{\mathrm{i}=1}^{\mathrm{N}} \Delta \phi_{\mathrm{i}}
$$

The same author pointed out that the histogram of phase difference has similar shape of the envelope of ground motion (see Fig. 2, for instance). The reason for this is already explained mathematically (See Papoulis 1977, Iwasaki et al. 1988, Yamane and Nagahashi 2002, and more recently, Nagao and Kanda 2013). Hence, $\sigma$ can be regarded as the duration of strong motion.

In this research, $\sigma$ was calculated in $0.1-1.0 \mathrm{~Hz}, 1.0-2.0 \mathrm{~Hz}, 2.0-3.0 \mathrm{~Hz}, 3.0-4.0 \mathrm{~Hz}, 4.0-$ $5.0 \mathrm{~Hz}, 5.0-6.0 \mathrm{~Hz}, 6.0-7.0 \mathrm{~Hz}, 7.0-8.0 \mathrm{~Hz}, 8.0-9.0 \mathrm{~Hz}$, and $9.0-10.0 \mathrm{~Hz}$ for each earthquake ground motion. Note that these frequency bands are signal frequency band, while the same frequency bands considered when computing $S C F$ values (Eq. 1) are oscillator frequency band. In this research, the relationships between the $S C F$ and $\sigma$ are investigated. 

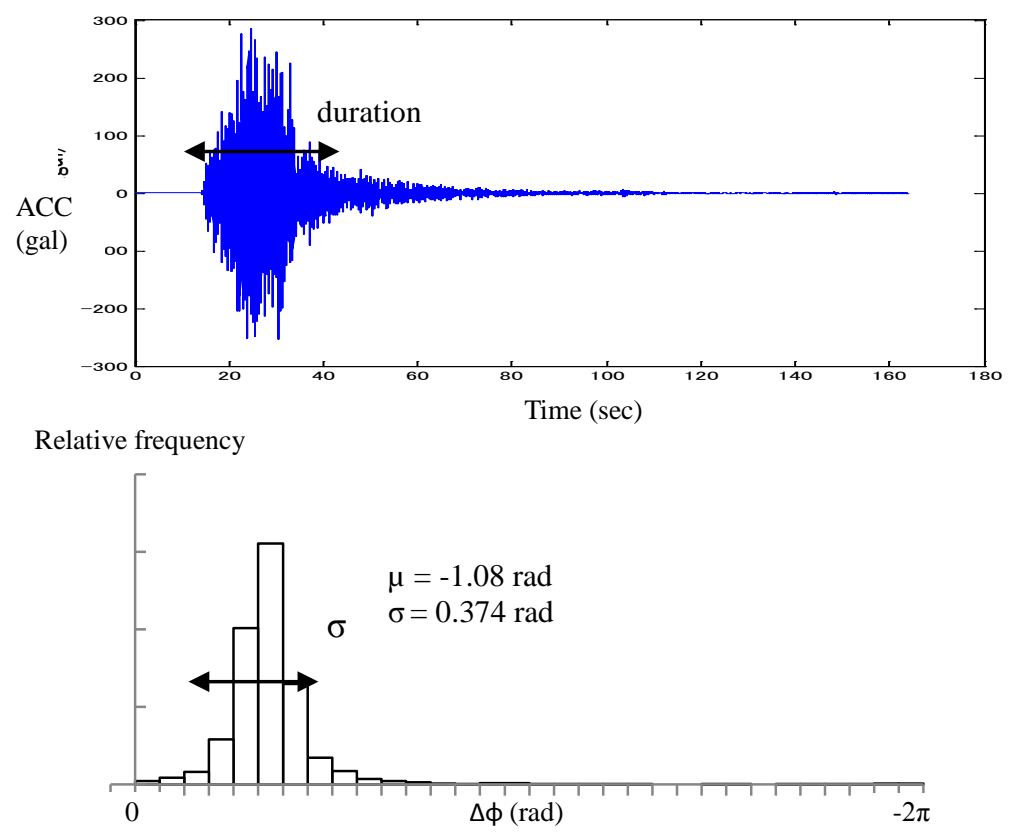

Fig. 2 Example of ground motion (upper) and phase difference distribution (lower)

\section{STRONG GROUND MOTION DATA SET}

Earthquake events after 1995 were considered in this research. After 1995 Hyogoken-nanbu earthquake in Kobe, Japan's K-NET and KiK-net projects were initiated, and researchers began to utilize ground-surface and borehole acceleration records obtained in a huge number of earthquakes. Especially seventeen earthquake events, mostly of $M_{w}$ greater than 6.5, were chosen in this research. See Table 1. These include all three types of rupture mechanisms, so that results from different-rupture-type-events can be compared. The information on the earthquake sources are provided by the National Research Institute for Earth Science and Disaster Prevention, Japan (http://www.kyoshin.bosai.go.jp).

A number of acceleration records are obtained for each event. All ground motions analyzed are KiK-net records. The sample size $N$ is 32768 in all ground motions. For original ground motion records in earthquake $1,2,3,4,5,9,10,13,14$, and 15 , the sampling frequency is $200 \mathrm{~Hz}$, while for those in other earthquakes, the sampling frequency is $100 \mathrm{~Hz}$. In this study, linear interpolation between two neighboring accelerations (amplitudes) was done for ground motion records whose sampling frequency is $100 \mathrm{~Hz}$. In this study, the horizontal records (N-S components) obtained within $100 \mathrm{~km}$ of the epicentral distance were basically considered. However, three interplate earthquakes occurred off the coast of the Pacific Ocean and the numbers of records within $100 \mathrm{~km}$ are few. For that reason, records up to $150 \mathrm{~km}$ for 2005 Miyagiken oki earthquake and $200 \mathrm{~km}$ for 2003 Tokachi oki and 2011 Sanriku oki earthquake were used. As can be seen, the $1^{\text {st }}$ to $8^{\text {th }}$ earthquakes are crustal, the $9^{\text {th }}$ to $12^{\text {th }}$ are interplate, and the $13^{\text {th }}$ to $17^{\text {th }}$ are intraplate earthquakes.

All ground motion records are borehole data obtained at underground points where the Vs ranges from $400 \mathrm{~m} / \mathrm{s}$ to $3300 \mathrm{~m} / \mathrm{s}$. Moreover, the number of analyzed records and the minimum and maximum epicentral distances for each earthquake are shown in Table 2. 
Table 1 Earthquakes’ data analyzed in this study

\begin{tabular}{|c|c|c|c|c|c|c|}
\hline No. & Name & $\begin{array}{c}\text { Occurrence } \\
\text { date }\end{array}$ & $\mathrm{M}_{\mathrm{w}}$ & Depth & Mechanism & Hypocenter location \\
\hline 1 & Tottoriken seibu & $2000 / 10 / 06$ & 6.6 & $11 \mathrm{~km}$ & Crustal, strike & Long. 133.35 Lat. 35.28 \\
\hline 2 & Niigataken chuetsu & $2004 / 10 / 23$ & 6.6 & $13 \mathrm{~km}$ & Crustal, reverse & Long. 138.87 Lat. 37.29 \\
\hline 3 & Fukuokaken seihouoki & $2005 / 03 / 20$ & 6.6 & $9 \mathrm{~km}$ & Crustal, strike & Long. 130.18 Lat. 33.74 \\
\hline 4 & Notohanto oki & $2007 / 03 / 25$ & 6.7 & $11 \mathrm{~km}$ & Crustal, reverse & Long. 136.69 Lat. 37.22 \\
\hline 5 & Niigataken chuetsu oki & $2007 / 07 / 16$ & 6.6 & $17 \mathrm{~km}$ & Crustal, reverse & Long. 138.61 Lat. 37.56 \\
\hline 6 & Iwate - Miyagi nairiku & $2008 / 06 / 14$ & 6.9 & $8 \mathrm{~km}$ & Crustal, reverse & Long. 140.88 Lat. 39.03 \\
\hline 7 & Naganoken-hokubu & $2011 / 03 / 12$ & 6.35 & $8 \mathrm{~km}$ & Crustal, reverse & Long. 138.60 Lat. 36.98 \\
\hline 8 & Fukushimaken hamadori & $2011 / 04 / 11$ & 7.1 & $6 \mathrm{~km}$ & Crustal, normal & Long. 140.67 Lat. 36.95 \\
\hline 9 & Tokachi oki & $2003 / 09 / 26$ & 7.9 & $42 \mathrm{~km}$ & Interplate, reverse & Long. 144.07 Lat. 41.78 \\
\hline 10 & Miyagiken oki & $2005 / 08 / 16$ & 7.1 & $45 \mathrm{~km}$ & Interplate, reverse & Long. 142.28 Lat. 38.15 \\
\hline 11 & Sanriku oki & $2011 / 03 / 09$ & 7.2 & $8 \mathrm{~km}$ & Interplate, reverse & Long. 143.28 Lat. 38.33 \\
\hline 12 & Ibarakiken oki & $2011 / 03 / 11$ & 7.7 & $43 \mathrm{~km}$ & Interplate, reverse & Long. 141.26 Lat. 36.11 \\
\hline 13 & Geiyo & $2001 / 03 / 24$ & 6.7 & $51 \mathrm{~km}$ & Intraplate & Long. 132.71 Lat. 34.12 \\
\hline 14 & Iwateken nairikunanbu & $2001 / 12 / 02$ & 6.5 & $122 \mathrm{~km}$ & Intraplate & Long. 141.26 Lat. 39.40 \\
\hline 15 & Miyagiken oki & $2003 / 05 / 26$ & 7.0 & $70 \mathrm{~km}$ & Intraplate & Long. 141.68 Lat. 38.81 \\
\hline 16 & Surugawan & $2009 / 08 / 11$ & 6.2 & $23 \mathrm{~km}$ & Intraplate & Long. 138.50 Lat. 34.78 \\
\hline 17 & Miyagiken oki & $2011 / 04 / 07$ & 7.1 & $66 \mathrm{~km}$ & Intraplate & Long. 141.92 Lat. 38.20 \\
\hline
\end{tabular}

Table 2 The number of analyzed records and the min. and max. epicentral distances for each earthquake

\begin{tabular}{|c|c|c|c|c|}
\hline No. & Name & Min. distance & Max. distance & No. of records \\
\hline 1 & Tottoriken seibu & $7 \mathrm{~km}$ & $100 \mathrm{~km}$ & 33 \\
\hline 2 & Niigataken chuetsu & $15 \mathrm{~km}$ & $99 \mathrm{~km}$ & 31 \\
\hline 3 & Fukuokaken seihouoki & $36 \mathrm{~km}$ & $99 \mathrm{~km}$ & 22 \\
\hline 4 & Notohanto oki & $35 \mathrm{~km}$ & $92 \mathrm{~km}$ & 7 \\
\hline 5 & Niigataken chuetsu oki & $29 \mathrm{~km}$ & $100 \mathrm{~km}$ & 23 \\
\hline 6 & Iwate - Miyagi nairiku & $3 \mathrm{~km}$ & $100 \mathrm{~km}$ & 38 \\
\hline 7 & Naganoken-hokubu & $16 \mathrm{~km}$ & $97 \mathrm{~km}$ & 36 \\
\hline 8 & Fukushimaken hamadori & $19 \mathrm{~km}$ & $96 \mathrm{~km}$ & 29 \\
\hline 9 & Tokachi oki & $104 \mathrm{~km}$ & $150 \mathrm{~km}$ & 11 \\
\hline 10 & Miyagiken oki & $91 \mathrm{~km}$ & $148 \mathrm{~km}$ & 16 \\
\hline 11 & Sanriku oki & $157 \mathrm{~km}$ & $200 \mathrm{~km}$ & 13 \\
\hline 12 & Ibarakiken oki & $57 \mathrm{~km}$ & $100 \mathrm{~km}$ & 10 \\
\hline 13 & Geiyo & $19 \mathrm{~km}$ & $98 \mathrm{~km}$ & 36 \\
\hline 14 & Iwateken nairikunanbu & $8 \mathrm{~km}$ & $100 \mathrm{~km}$ & 45 \\
\hline 15 & Miyagiken oki & $13 \mathrm{~km}$ & $98 \mathrm{~km}$ & 21 \\
\hline 16 & Surugawan & $21 \mathrm{~km}$ & $100 \mathrm{~km}$ & 37 \\
\hline 17 & Miyagiken oki & $83 \mathrm{~km}$ & $98 \mathrm{~km}$ & 7 \\
\hline
\end{tabular}

Ground motion records of the 2011 off the Pacific coast of Tohoku earthquake $\left(M_{w}=9.0\right)$ were not considered in this research because of a special characteristic of the records. As shown in Fig. 3, some acceleration records clearly exhibit multiple wave packets, causing the total energy input relating the energy spectrum extremely high while making the peak response quantities relating the response spectra relatively smaller than those that can be expected from such a large magnitude event. 


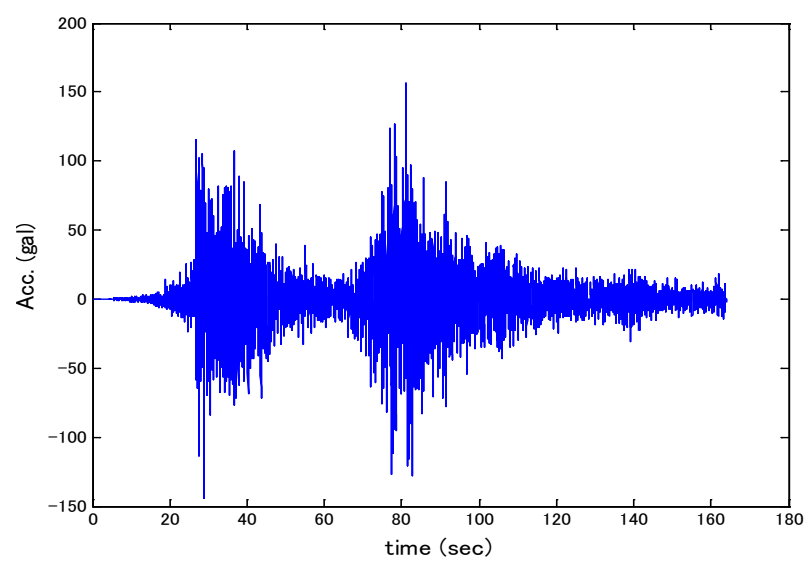

Fig. 3 Ground motion example of the 2011 off the Pacific coast of Tohoku earthquake

\section{RESULTS}

\section{Results for $\sigma$-SCF relationships}

In Nagao and Kanda (2012), it was suggested that $\sigma$ would be estimated for each earthquake type, i.e., crustal, interplate, and intraplate. Hence obtained $\sigma$-SCF relationships are presented for each type at first. In Fig. 4, obtained $\sigma$-SCF relationships with $5 \%$ damping in $0.1-1.0 \mathrm{~Hz}$ and $9.0-10.0 \mathrm{~Hz}$ are presented. From Fig.4, SCFs always increase as $\sigma$ increase in both frequency bands. However, the rate of the increase is larger in the larger frequency band. Moreover, obtained $\sigma$-SCF relationships are similar among all earthquakes chosen for this research.

The influences from site conditions on the $\sigma$-SCF relationships were also investigated. In Fig. 5, the $\sigma$-SCF relationships with the $V s$ less than $700 \mathrm{~m} / \mathrm{s}$ are superimposed by those with the $V s$ more than or equals to $700 \mathrm{~m} / \mathrm{s}$ in $0.1-1.0 \mathrm{~Hz}$ and $9.0-10.0 \mathrm{~Hz}$ (ten records were eliminated, because the soil profile information are not available for the records). From Fig. 5, the $\sigma$-SCF relationships might not be affected by the site conditions.

Based on the finding that the $\sigma$-SCF relationships were influenced only by frequency, results of all earthquake types and site conditions combined were considered for the regression analysis. Fig.6 shows $\sigma$-SCF relationships in all frequency bands with $\zeta=5 \%$. From Fig. 6 , the slope is steeper for higher frequency bands, and all of the plots could be expressed by a linear regression model. See the following equation.

$$
\operatorname{SCF}\left(f \cdot b_{\cdot}, \zeta_{j}\right)=a_{i, j}+b_{i, j} \sigma
$$

where f.b. ${ }_{\cdot i}$ is the $i$ th frequency band (i.e. $f \cdot b_{\cdot 1}=0.1-1.0 \mathrm{~Hz}, f . b_{.2}=1.0-2.0 \mathrm{~Hz}, \ldots, f \cdot b_{\cdot 10}=9.0-10.0$ $\mathrm{Hz}$ ), while $\zeta_{j}$ is the $j$ th damping ratio (i.e. $\zeta_{1}=0 \%, \zeta_{2}=1 \%, \ldots, \zeta_{9}=50 \%$ ). The term $a$ is the intercept component, whereas the term $b$ is the slope component. The term $a$ represents the $S C F$ when $\sigma$ equals to $0 \mathrm{rad}$. If $\sigma$ equals to $0 \mathrm{rad}$, all of the phase differences should be the same value. From the physical meaning of the phase difference (e.g. Iwasaki et al. 1988, Yamane and Nagahashi 2002, and Nagao and Kanda 2013), ground motions whose $\sigma$ values equal to 0 rad are pulse waves. Table 3 lists all of the estimated coefficients $a$ and $b$. In addition, the standard errors, denoted as $s$, are listed. All of the standard errors $s$ were assumed to be constant along $\sigma$. In Fig.6, regression results when the SCF are expressed by the following form (as is done in Akiyama and Kitamura 2006, Miyake 2006, and Okano et al. 2009) are also shown as dot lines as a comparison: 


$$
S C F=c \sqrt{\sigma}
$$

When $\sigma$ is small, the linear regression results overestimate the $S C F$ in $5.0 \mathrm{~Hz}$ and higher, while regression results using Eq. (6) underestimate the $S C F$ in $0.1-5.0 \mathrm{~Hz}$. The three previous studies (Akiyama and Kitamura 2006, Miyake 2006, and Okano et al. 2009) assumed that the duration of strong motion is proportional to the total energy of the ground motion. Therefore, those studies modeled the $V_{E}$ (square root of the input energy) by the square root of the duration of strong motion. However, the duration of strong motion can be influenced by factors such as the seismic path and rupture mechanism. For instance, Nagao and Kanda (2012) observed that $\sigma$ values of ground motions whose energy levels are almost the same could be mainly influenced by the rupture mechanism. Hence, their assumption is not valid especially for non-stationary waves such as natural ground motions. In this study, the SCF is not considered as a function of the square root of the duration and is alternatively modeled by the simplest form (i.e. the linear regression model).

Fig. 7 illustrates the parameter estimates with respect to the damping ratio and frequency band. Cases of $\zeta=0,1,5,10$, and $20 \%$ are presented. From Fig. 7, there are tendencies that all of the parameters $a, b$, and $s$ increase as the frequency or damping ratio increases. In case of no-damping, however, no clear tendencies could be found and all parameters may be seen as constant.

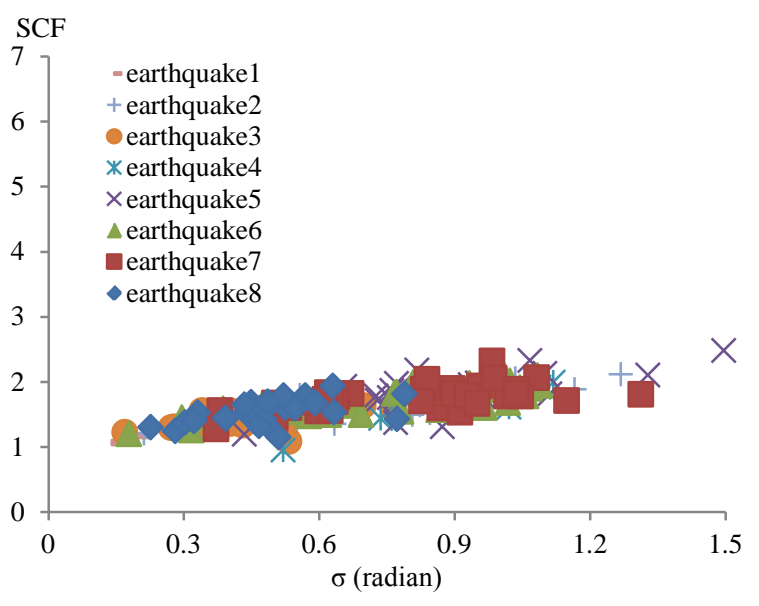

a) $\sigma-\mathrm{DCF}(0.1-1.0 \mathrm{~Hz}, 5 \%)$ plot (crustal)

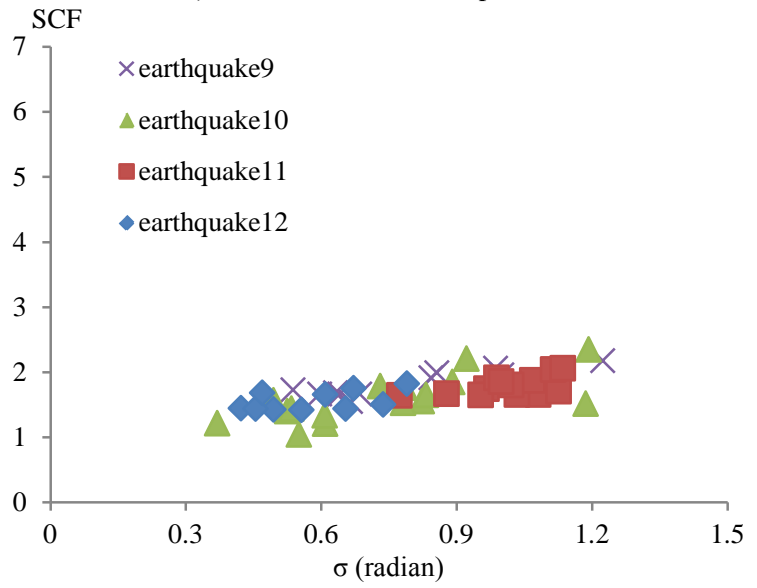

b) $\sigma-\mathrm{DCF}(0.1-1.0 \mathrm{~Hz}, 5 \%)$ plot (interplate)

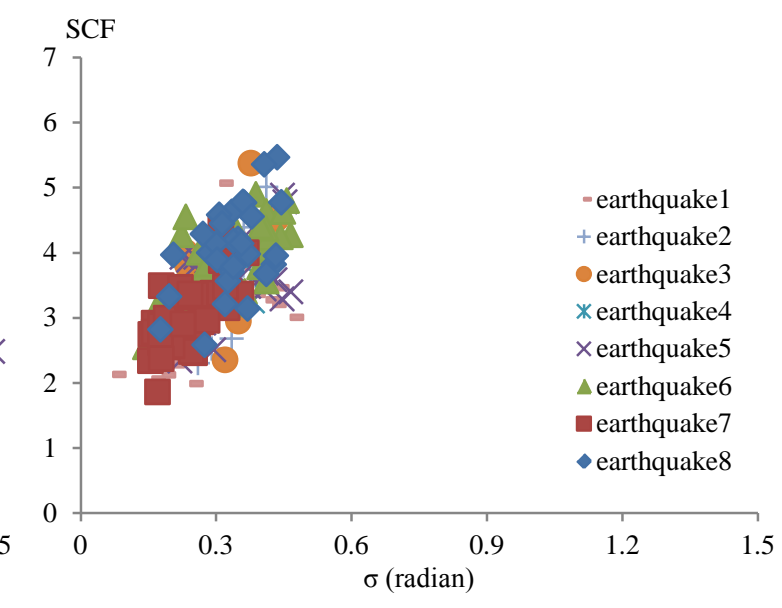

d) $\sigma-\mathrm{DCF}(9.0-10.0 \mathrm{~Hz}, 5 \%)$ plot (crustal)

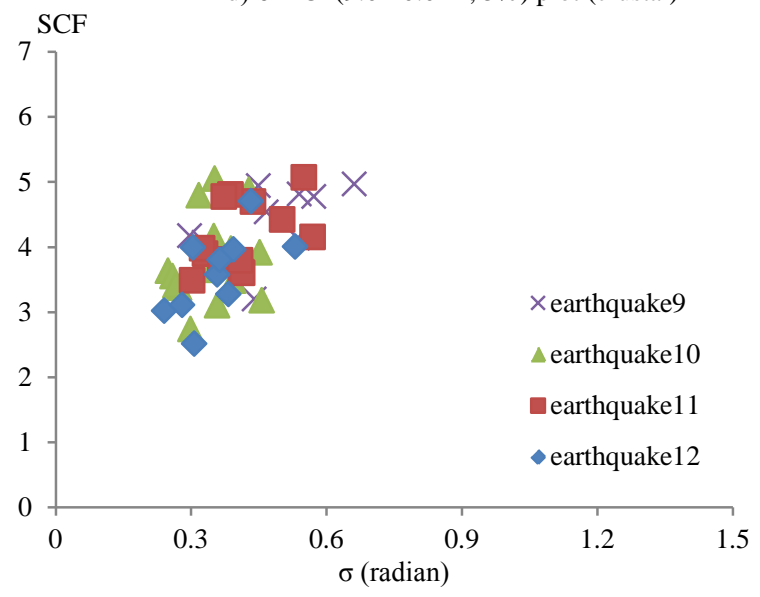

e) $\sigma-\mathrm{DCF}(9.0-10.0 \mathrm{~Hz}, 5 \%)$ plot (interplate)

Fig.4 Examples of $\sigma$-SCF relations with $\zeta=5 \%$ for each earthquake type 
Fig.4 continued

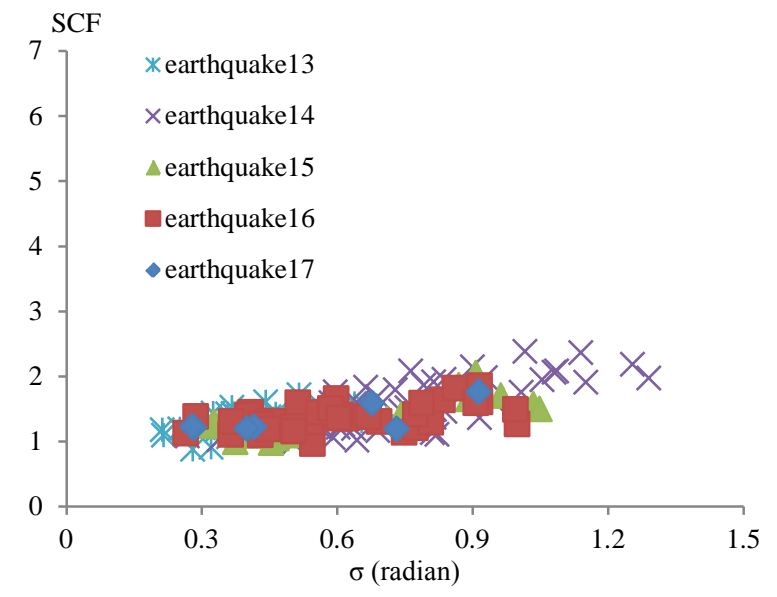

c) $\sigma-\mathrm{DCF}(0.1-1.0 \mathrm{~Hz}, 5 \%)$ plot (intraplate)

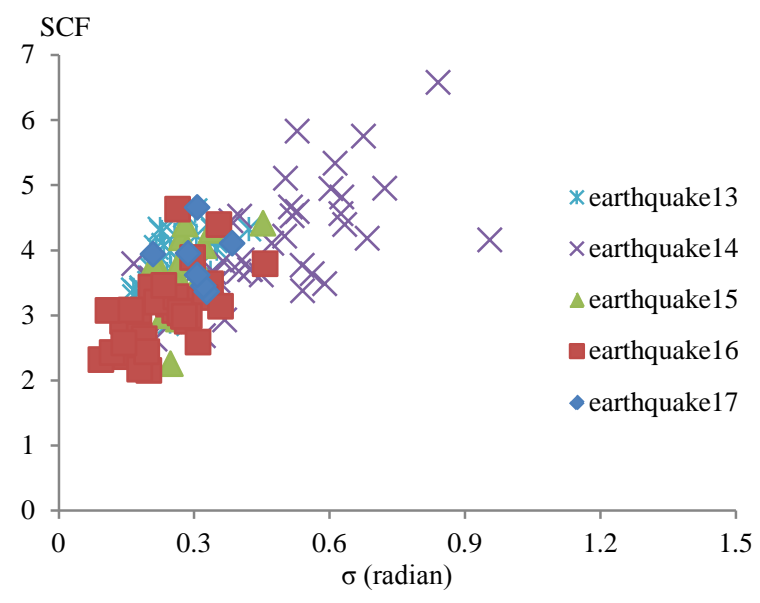

f) $\sigma-\mathrm{DCF}(9.0-10.0 \mathrm{~Hz}, 5 \%)$ plot (intraplate)

Fig.4 Examples of $\sigma$-SCF relations with $\zeta=5 \%$ for each earthquake type

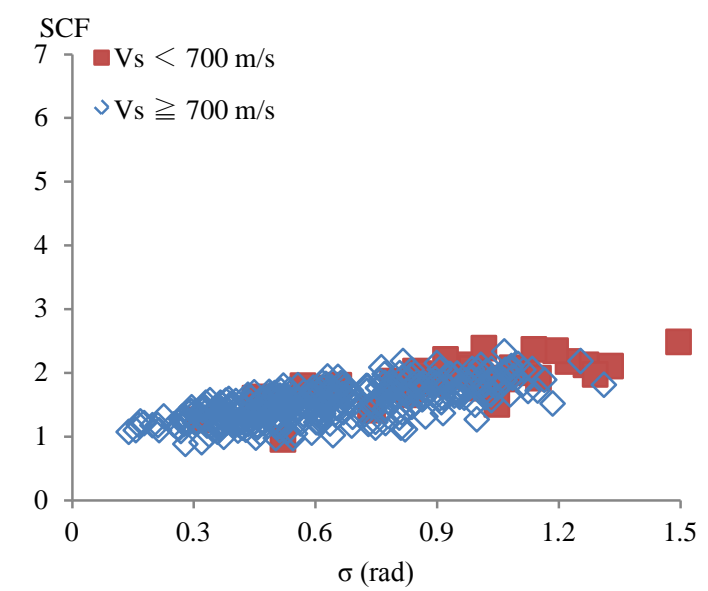

a) $0.1-1.0 \mathrm{~Hz}$

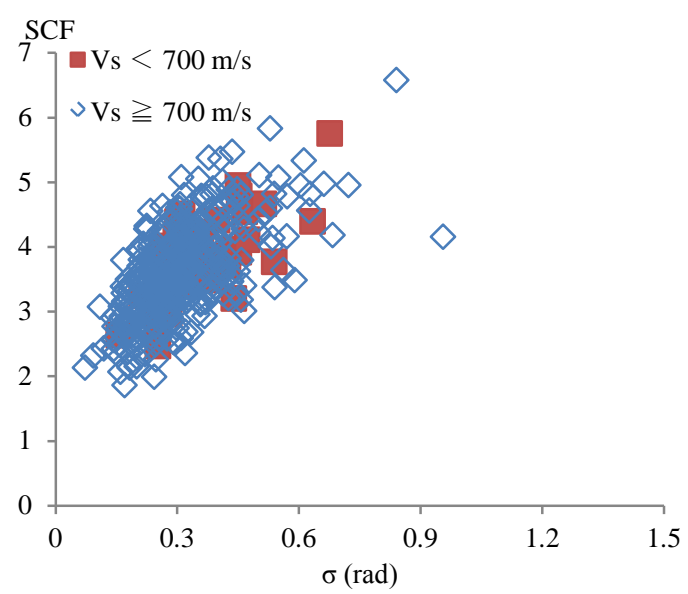

b) $9.0-10.0 \mathrm{~Hz}$

Fig.5 Examples of $\sigma$-SCF relations with $\zeta=5 \%$ for different site conditions 


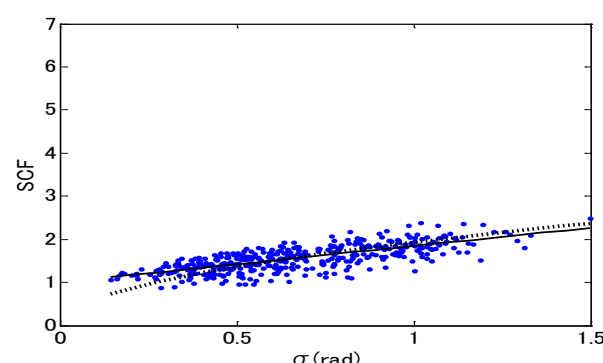

a) $0.1-1.0 \mathrm{~Hz}$

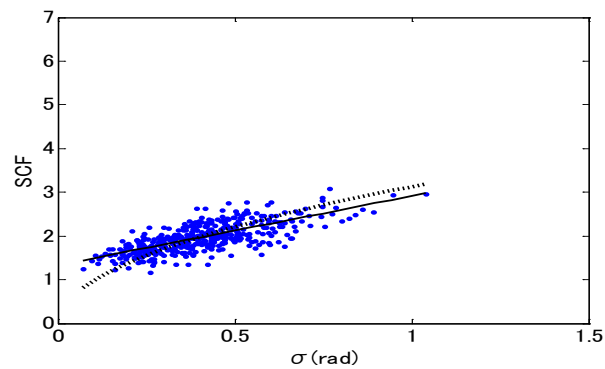

b) $1.0-2.0 \mathrm{~Hz}$

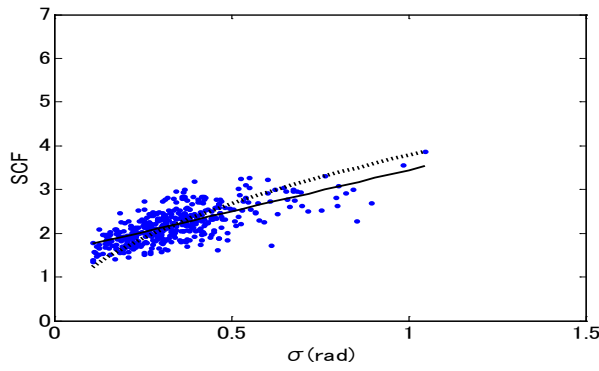

c) $2.0-3.0 \mathrm{~Hz}$

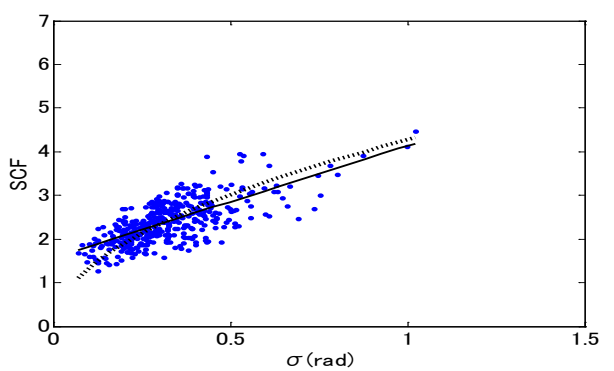

d) $3.0-4.0 \mathrm{~Hz}$

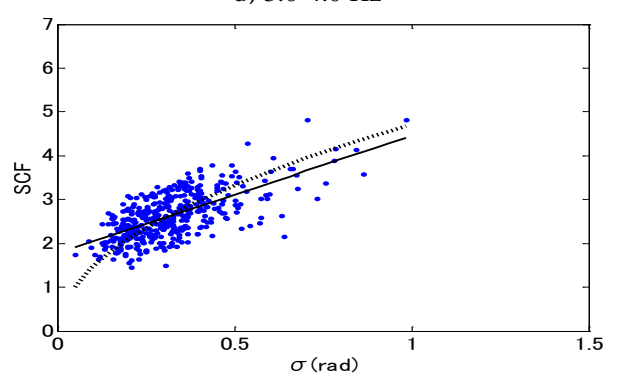

e) $4.0-5.0 \mathrm{~Hz}$

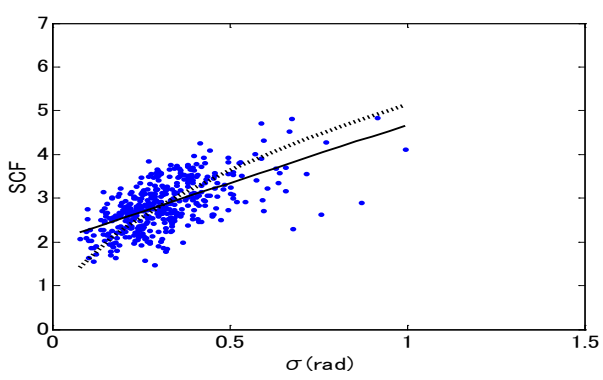

f) $5.0-6.0 \mathrm{~Hz}$

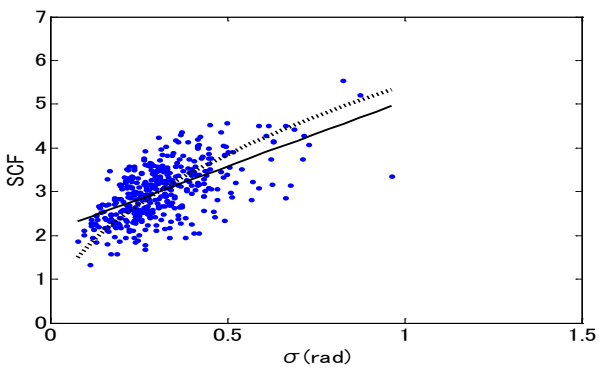

g) $6.0-7.0 \mathrm{~Hz}$

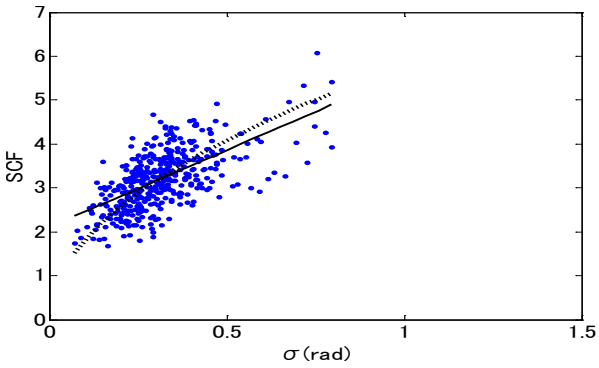

h) $7.0-8.0 \mathrm{~Hz}$

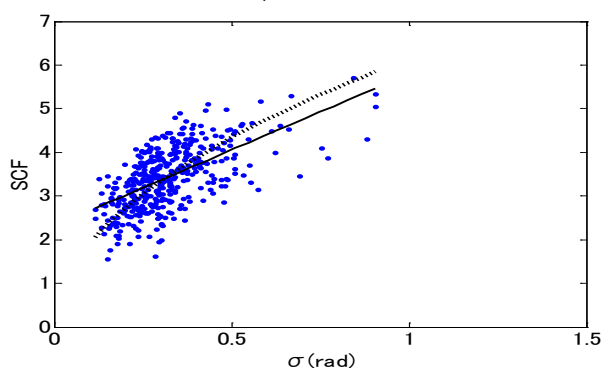

i) $8.0-9.0 \mathrm{~Hz}$

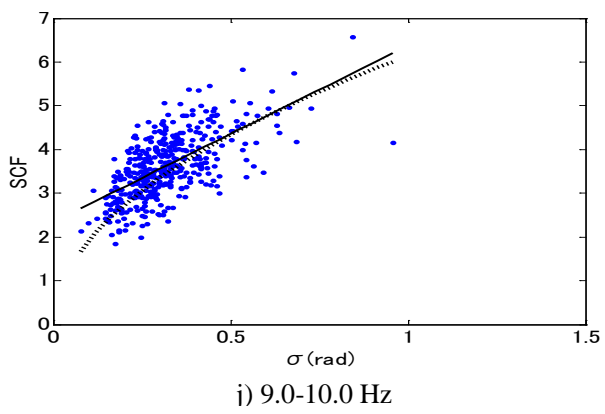

Fig. $6 \sigma$-SCF relations with $\zeta=5 \%$ in all frequency bands (continuous line: linear model, dot line: square root model) 
Table 3 Parameters estimated for individual damping ratio and frequency band for SCF estimate

\begin{tabular}{|c|c|c|c|c|c|c|c|c|c|c|c|c|}
\hline & \multicolumn{3}{|c|}{$\zeta=0 \%$} & \multicolumn{3}{|c|}{$\zeta=1 \%$} & \multicolumn{3}{|c|}{$\zeta=2 \%$} & \multicolumn{3}{|c|}{$\zeta=5 \%$} \\
\hline f.b. & $a_{i, 1}$ & $\mathrm{~b}_{\mathrm{i}, 1}$ & $\mathrm{~S}_{1}$ & $\mathrm{a}_{\mathrm{i}, 2}$ & $b_{i, 2}$ & $\mathrm{~S}_{2}$ & $\mathrm{a}_{\mathrm{i}, 3}$ & $\mathrm{~b}_{\mathrm{i}, 3}$ & $\mathrm{~S}_{3}$ & $\mathrm{a}_{\mathrm{i}, 4}$ & $\mathrm{~b}_{\mathrm{i}, 4}$ & $\mathrm{~S}_{4}$ \\
\hline $0.1-1.0 \mathrm{~Hz}$ & 0.754 & 0.014 & 0.041 & 0.834 & 0.349 & 0.086 & 0.883 & 0.521 & 0.120 & 1.004 & 0.843 & 0.201 \\
\hline $1.0-2.0 \mathrm{~Hz}$ & 0.803 & -0.058 & 0.021 & 0.968 & 0.624 & 0.077 & 1.085 & 0.947 & 0.123 & 1.338 & 1.578 & 0.229 \\
\hline $3.0-4.0 \mathrm{~Hz}$ & 0.789 & -0.051 & 0.028 & 1.059 & 1.070 & 0.133 & 1.239 & 1.539 & 0.207 & 1.580 & 2.558 & 0.354 \\
\hline $4.0-5.0 \mathrm{~Hz}$ & 0.791 & -0.050 & 0.025 & 1.103 & 1.281 & 0.148 & 1.324 & 1.763 & 0.228 & 1.791 & 2.660 & 0.397 \\
\hline $7.0-8.0 \mathrm{~Hz}$ & 0.795 & -0.063 & 0.027 & 1.267 & 1.627 & 0.200 & 1.535 & 2.301 & 0.302 & 2.119 & 3.496 & 0.521 \\
\hline $8.0-9.0 \mathrm{~Hz}$ & 0.788 & -0.043 & 0.024 & 1.350 & 1.658 & 0.235 & 1.685 & 2.247 & 0.347 & 2.331 & 3.469 & 0.556 \\
\hline $9.0-10.0 \mathrm{~Hz}$ & 0.794 & -0.050 & 0.022 & 1.385 & 1.810 & 0.224 & 1.702 & 2.565 & 0.335 & 2.352 & 4.028 & 0.557 \\
\hline
\end{tabular}

\begin{tabular}{|c|c|c|c|c|c|c|c|c|c|c|c|c|}
\hline & \multicolumn{3}{|c|}{$\zeta=10 \%$} & \multicolumn{3}{|c|}{$\zeta=20 \%$} & \multicolumn{3}{|c|}{$\zeta=30 \%$} & \multicolumn{3}{|c|}{$\zeta=40 \%$} \\
\hline f.b. & $a_{i, 5}$ & $\mathrm{~b}_{\mathrm{i}, 5}$ & $\mathrm{~S}_{5}$ & $\mathrm{a}_{\mathrm{i}, 6}$ & $\mathrm{~b}_{\mathrm{i}, 6}$ & $\mathrm{~S}_{6}$ & $\mathrm{a}_{\mathrm{i}, 7}$ & $\mathrm{~b}_{\mathrm{i}, 7}$ & $\mathrm{~S}_{7}$ & $\mathrm{a}_{\mathrm{i}, 8}$ & $\mathrm{~b}_{\mathrm{i}, 8}$ & $\mathrm{~S}_{8}$ \\
\hline $0.1-1.0 \mathrm{~Hz}$ & 1.163 & 1.176 & 0.305 & 1.411 & 1.602 & 0.459 & 1.617 & 1.890 & 0.575 & 1.800 & 2.101 & 0.670 \\
\hline $2.0-3.0 \mathrm{~Hz}$ & 1.983 & 2.639 & 0.440 & 2.596 & 3.718 & 0.662 & 3.065 & 4.609 & 0.836 & 3.439 & 5.449 & 0.991 \\
\hline $3.0-4.0 \mathrm{~Hz}$ & 1.968 & 3.751 & 0.521 & 2.580 & 5.376 & 0.751 & 3.114 & 6.488 & 0.921 & 3.585 & 7.410 & 1.064 \\
\hline $4.0-5.0 \mathrm{~Hz}$ & 2.283 & 3.810 & 0.595 & 2.991 & 5.522 & 0.854 & 3.548 & 6.916 & 1.059 & 4.054 & 8.021 & 1.226 \\
\hline $7.0-8.0 \mathrm{~Hz}$ & 2.841 & 4.735 & 0.771 & 3.865 & 6.615 & 1.109 & 4.716 & 7.942 & 1.354 & 5.463 & 9.042 & 1.548 \\
\hline $8.0-9.0 \mathrm{~Hz}$ & 3.060 & 4.922 & 0.808 & 4.141 & 6.949 & 1.161 & 4.982 & 8.510 & 1.399 & 5.727 & 9.827 & 1.587 \\
\hline $9.0-10.0 \mathrm{~Hz}$ & 3.124 & 5.611 & 0.816 & 4.210 & 7.910 & 1.167 & 5.109 & 9.517 & 1.433 & 5.900 & 10.86 & 1.647 \\
\hline
\end{tabular}

\begin{tabular}{|c|c|c|c|}
\hline & \multicolumn{3}{|c|}{$\zeta=50 \%$} \\
\hline f.b. & $\mathrm{a}_{\mathrm{i}, 9}$ & $\mathrm{~b}_{\mathrm{i}, 9}$ & $\mathrm{~s}_{9}$ \\
\hline $0.1-1.0 \mathrm{~Hz}$ & 1.967 & 2.269 & 0.752 \\
\hline $1.0-2.0 \mathrm{~Hz}$ & 2.846 & 5.293 & 0.946 \\
\hline $2.0-3.0 \mathrm{~Hz}$ & 3.768 & 6.223 & 1.135 \\
\hline $3.0-4.0 \mathrm{~Hz}$ & 4.002 & 8.243 & 1.197 \\
\hline $4.0-5.0 \mathrm{~Hz}$ & 4.526 & 8.951 & 1.375 \\
\hline $5.0-6.0 \mathrm{~Hz}$ & 5.265 & 8.854 & 1.491 \\
\hline $6.0-7.0 \mathrm{~Hz}$ & 5.816 & 9.152 & 1.625 \\
\hline $7.0-8.0 \mathrm{~Hz}$ & 6.133 & 10.01 & 1.726 \\
\hline $8.0-9.0 \mathrm{~Hz}$ & 6.408 & 10.94 & 1.762 \\
\hline $9.0-10.0 \mathrm{~Hz}$ & 6.601 & 12.09 & 1.841 \\
\hline
\end{tabular}




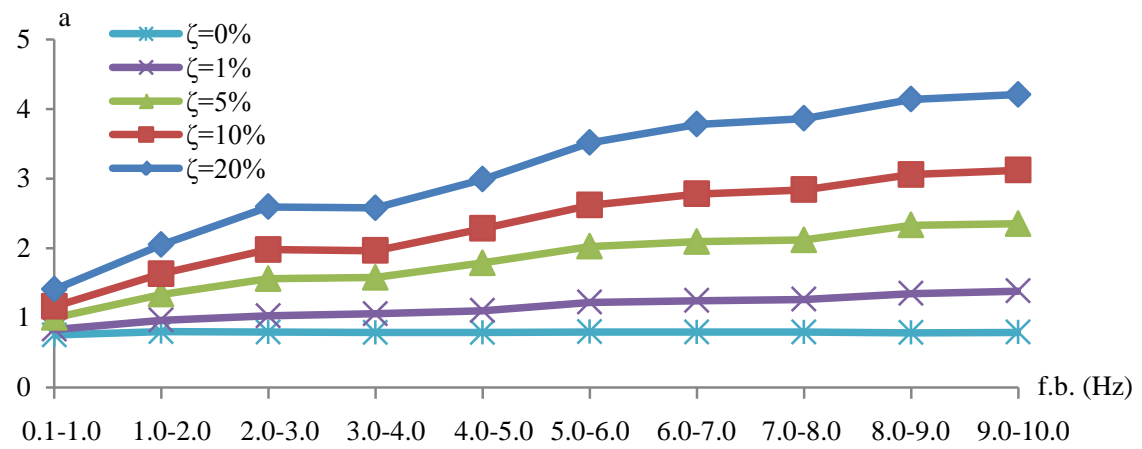

a) Parameter a

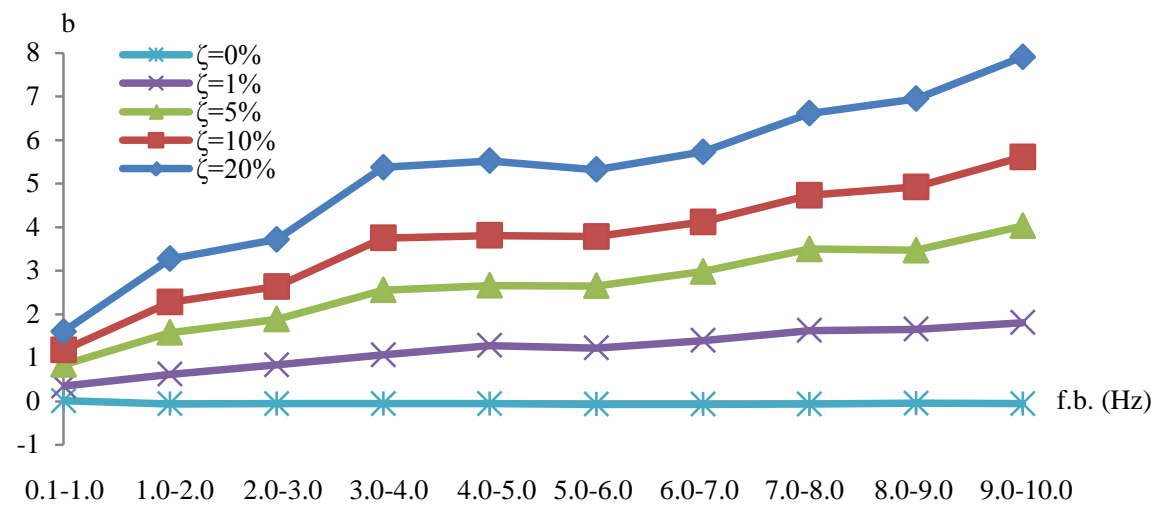

b) Parameter b

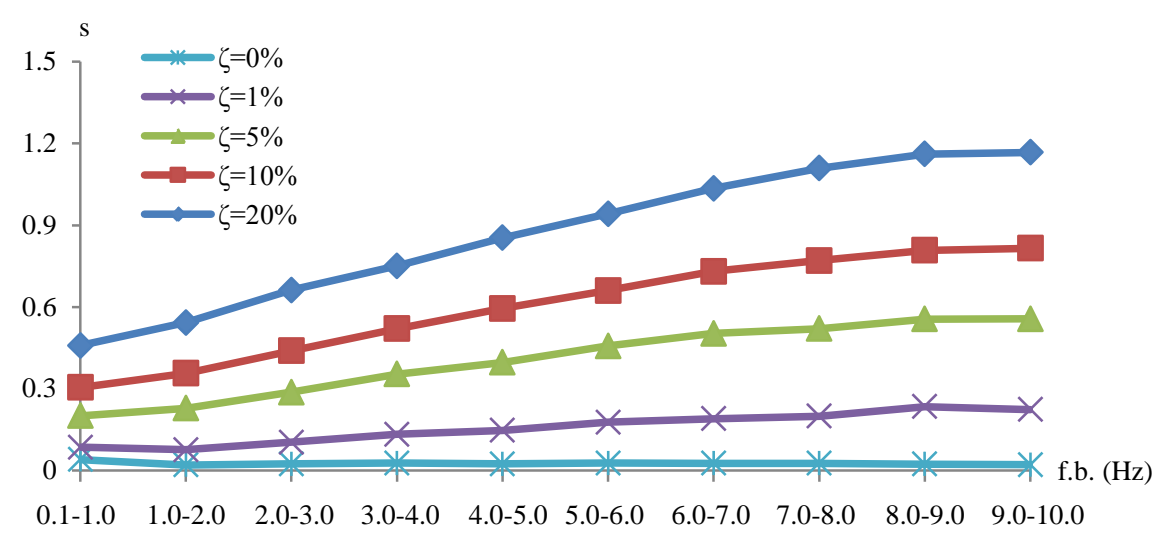

c) Standard error s

Fig. 7 Dependence of the parameters and standard error on the damping ratio and frequency bands

\section{Damping effects on response spectrum and energy spectrum}

In this section, though they are not main points of this study and they were already discussed in previous literatures, damping effects on the response spectrum and energy spectrum are discussed. For convenience, the following expressions are used.

$$
\begin{aligned}
& D C F_{R}(f . b ., \zeta)=\frac{S_{a}(f . b ., \zeta)}{S_{a}(f \cdot b ., 5 \%)} \\
& D C F_{E}(f . b ., \zeta)=\frac{V_{E}(f \cdot b ., \zeta)}{V_{E}(f . b ., 5 \%)}
\end{aligned}
$$


A few examples of obtained $\sigma-D C F_{R}$ and $\sigma-D C F_{E}$ relations are shown in Fig. 8 and Fig. 9, respectively. As was discussed in Nagao and Kanda (2013), in low frequency bands such as $0.1-1.0$ $\mathrm{Hz}$, the $D C F_{R}$ approaches unity as $\sigma$ decreases, while the opposite tendency can be observed in higher frequency bands. On the other hands, as for $\sigma-D C F_{E}$ relations, damping effect may be insignificant in any frequency ranges, as was discussed in Kato and Akiyama (1975). Linear regression model was chosen to represent each of the relationships. See Eq. (9) and Eq. (10).

$$
\begin{aligned}
& D C F_{R}\left(f \cdot b_{\cdot i}, \zeta_{j}\right)=c_{i, j}+d_{i, j} \sigma \\
& D C F_{E}\left(f \cdot b_{\cdot i}, \zeta_{j}\right)=e_{i, j}+f_{i, j} \sigma
\end{aligned}
$$

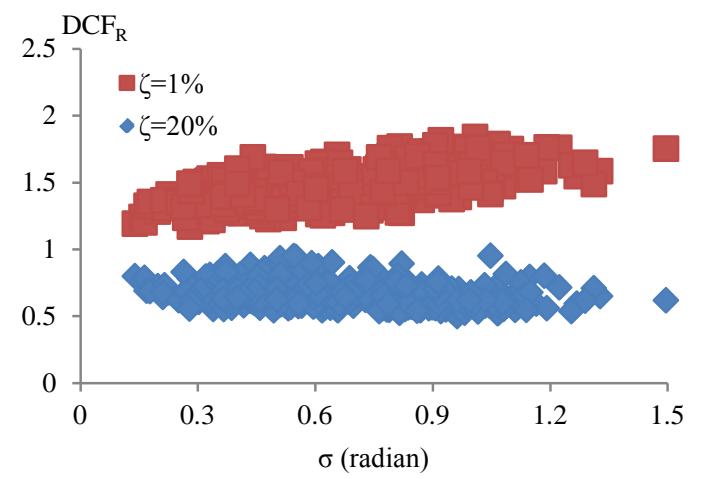

a) $0.1-1.0 \mathrm{~Hz}$

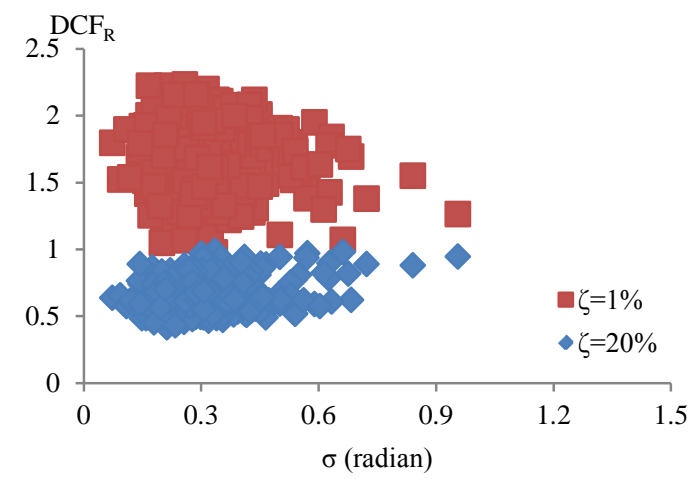

b) $9.0-10.0 \mathrm{~Hz}$

Fig. 8 Examples of $\sigma-\mathrm{DCF}_{\mathrm{R}}$ relations

Table 4 and Table 5 list all of the estimated coefficients and standard errors for the $\sigma$ - $D C F_{R}$ relations and the $\sigma-D C F_{E}$ relations, respectively. In Table 4, it should be noted that for damping ratio of $1 \%$ and $2 \%$, the slope component, $d$, decreases as frequency increases, whereas for the damping ratio of $10 \%$ and higher, the $d$ value becomes higher as frequency increases. This fact strongly reinforces the tendency observed in Fig. 8. As for Table 5, it should be noted that the standard errors are all within $7 \%$ for damping ratio of $1 \% \leq \zeta \leq 10 \%$, which is a reasonable damping ratio's range in many structures. In addition, because the slope component, $f$, is generally very small and the intercept component, $e$, always takes more or less unity, the $D C F_{E}$ were set equal to unity for the damping ratio range.

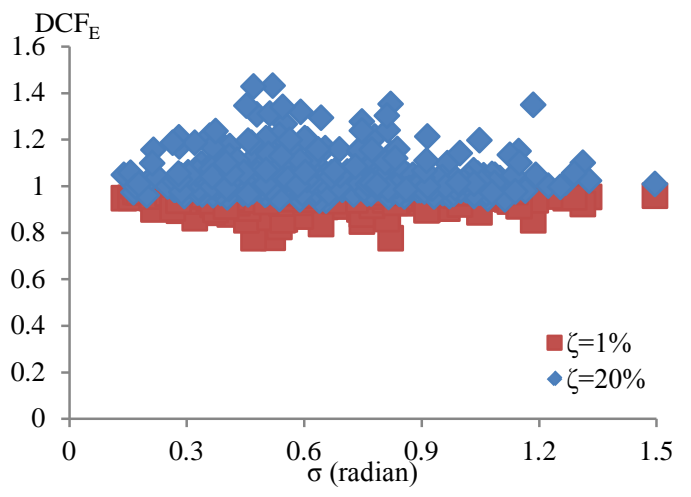

a) $0.1-1.0 \mathrm{~Hz}$

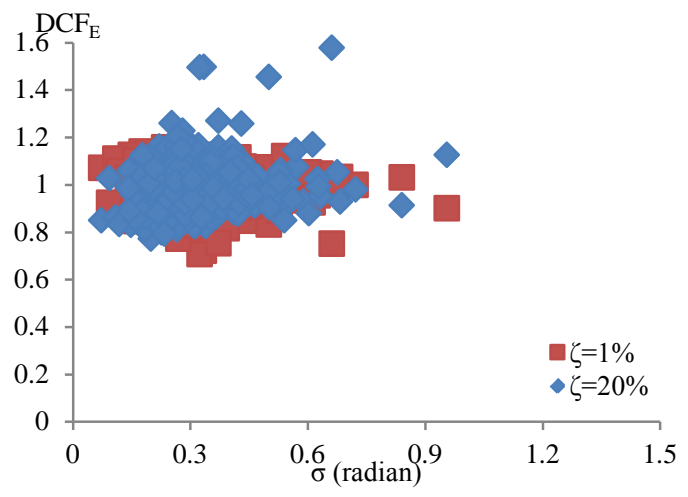

b) $9.0-10.0 \mathrm{~Hz}$

Fig. 9 Examples of $\sigma-\mathrm{DCF}_{\mathrm{E}}$ relations 
Table 4 Parameters estimated for individual damping ratio and frequency band for $D C F_{R}$ estimate

\begin{tabular}{|c|c|c|c|c|c|c|c|c|c|c|c|c|}
\hline & \multicolumn{3}{|c|}{$\zeta=0 \%$} & \multicolumn{3}{|c|}{$\zeta=1 \%$} & \multicolumn{3}{|c|}{$\zeta=2 \%$} & \multicolumn{3}{|c|}{$\zeta=10 \%$} \\
\hline f.b. & $\mathrm{C}_{\mathrm{i}, 1}$ & $\mathrm{~d}_{\mathrm{i}, 1}$ & $\mathrm{~S}_{1}$ & $\mathrm{C}_{\mathrm{i}, 2}$ & $\mathrm{~d}_{\mathrm{i}, 2}$ & $\mathrm{~S}_{2}$ & $\mathrm{C}_{\mathrm{i}, 3}$ & $\mathrm{~d}_{\mathrm{i}, 3}$ & $\mathrm{~S}_{3}$ & $\mathrm{C}_{\mathrm{i}, 4}$ & $\mathrm{~d}_{\mathrm{i}, 4}$ & $\mathrm{~S}_{4}$ \\
\hline $0.1-1.0 \mathrm{~Hz}$ & 1.427 & 0.944 & 0.207 & 1.283 & 0.306 & 0.102 & 1.185 & 0.149 & 0.060 & 0.844 & -0.060 & 0.041 \\
\hline $1.0-2.0 \mathrm{~Hz}$ & 1.687 & 1.468 & 0.277 & 1.438 & 0.302 & 0.122 & 1.272 & 0.116 & 0.070 & 0.793 & -0.003 & 0.044 \\
\hline $3.0-4.0 \mathrm{~Hz}$ & 1.930 & 2.155 & 0.495 & 1.524 & 0.237 & 0.180 & 1.307 & 0.073 & 0.099 & 0.781 & 0.034 & 0.058 \\
\hline $4.0-5.0 \mathrm{~Hz}$ & 2.198 & 2.024 & 0.546 & 1.621 & 0.035 & 0.187 & 1.350 & -0.027 & 0.102 & 0.774 & 0.051 & 0.062 \\
\hline $7.0-8.0 \mathrm{~Hz}$ & 2.706 & 1.842 & 0.767 & 1.723 & -0.217 & 0.224 & 1.405 & -0.181 & 0.123 & 0.737 & 0.181 & 0.067 \\
\hline $8.0-9.0 \mathrm{~Hz}$ & 2.942 & 1.711 & 0.806 & 1.757 & -0.255 & 0.219 & 1.409 & -0.174 & 0.121 & 0.743 & 0.170 & 0.066 \\
\hline $9.0-10.0 \mathrm{~Hz}$ & 3.013 & 1.880 & 0.839 & 1.765 & -0.257 & 0.234 & 1.419 & -0.193 & 0.128 & 0.754 & 0.151 & 0.071 \\
\hline
\end{tabular}

\begin{tabular}{|c|c|c|c|c|c|c|c|c|c|c|c|c|}
\hline & \multicolumn{3}{|c|}{$\zeta=20 \%$} & \multicolumn{3}{|c|}{$\zeta=30 \%$} & \multicolumn{3}{|c|}{$\zeta=40 \%$} & \multicolumn{3}{|c|}{$\zeta=50 \%$} \\
\hline f.b. & $\mathrm{C}_{\mathrm{i}, 5}$ & $\mathrm{~d}_{\mathrm{i}, 5}$ & $\mathrm{~S}_{5}$ & $\mathrm{C}_{\mathrm{i}, 6}$ & $\mathrm{~d}_{\mathrm{i}, 6}$ & $\mathrm{~S}_{6}$ & $\mathrm{C}_{\mathrm{i}, 7}$ & $\mathrm{~d}_{\mathrm{i}, 7}$ & $\mathrm{~S}_{7}$ & $\mathrm{C}_{\mathrm{i}, 8}$ & $\mathrm{~d}_{\mathrm{i}, 8}$ & $\mathrm{~S}_{8}$ \\
\hline $0.1-1.0 \mathrm{~Hz}$ & 0.721 & -0.086 & 0.080 & 0.691 & -0.097 & 0.111 & 0.699 & -0.107 & 0.144 & 0.725 & -0.116 & 0.177 \\
\hline $1.0-2.0 \mathrm{~Hz}$ & 0.622 & 0.028 & 0.074 & 0.559 & 0.041 & 0.086 & 0.536 & 0.045 & 0.095 & 0.533 & 0.042 & 0.105 \\
\hline $3.0-4.0 \mathrm{~Hz}$ & 0.598 & 0.112 & 0.090 & 0.523 & 0.147 & 0.101 & 0.487 & 0.167 & 0.107 & 0.468 & 0.180 & 0.112 \\
\hline $4.0-5.0 \mathrm{~Hz}$ & 0.592 & 0.132 & 0.100 & 0.514 & 0.178 & 0.111 & 0.473 & 0.204 & 0.115 & 0.451 & 0.219 & 0.116 \\
\hline $7.0-8.0 \mathrm{~Hz}$ & 0.558 & 0.275 & 0.105 & 0.485 & 0.314 & 0.117 & 0.443 & 0.344 & 0.122 & 0.418 & 0.366 & 0.124 \\
\hline $8.0-9.0 \mathrm{~Hz}$ & 0.560 & 0.290 & 0.106 & 0.484 & 0.346 & 0.118 & 0.441 & 0.378 & 0.122 & 0.416 & 0.400 & 0.124 \\
\hline $9.0-10.0 \mathrm{~Hz}$ & 0.572 & 0.281 & 0.110 & 0.493 & 0.351 & 0.123 & 0.449 & 0.394 & 0.128 & 0.421 & 0.422 & 0.131 \\
\hline
\end{tabular}

Table 5 Parameters estimated for individual damping ratio and frequency band for $D C F_{E}$ estimate

\begin{tabular}{|c|c|c|c|c|c|c|c|c|c|c|c|c|}
\hline & \multicolumn{3}{|c|}{$\zeta=0 \%$} & \multicolumn{3}{|c|}{$\zeta=1 \%$} & \multicolumn{3}{|c|}{$\zeta=2 \%$} & \multicolumn{3}{|c|}{$\zeta=10 \%$} \\
\hline f.b. & $\mathrm{e}_{\mathrm{i}, 1}$ & $f_{i, 1}$ & $\mathrm{~s}_{1}$ & $e_{i, 2}$ & $f_{i, 2}$ & $\mathrm{~S}_{2}$ & $\mathrm{e}_{\mathrm{i}, 3}$ & $f_{i, 3}$ & $\mathrm{~S}_{3}$ & $\mathrm{e}_{\mathrm{i}, 4}$ & $f_{i, 4}$ & $\mathrm{~S}_{4}$ \\
\hline $0.1-1.0 \mathrm{~Hz}$ & 0.907 & -0.030 & 0.045 & 0.942 & 0.011 & 0.033 & 0.963 & 0.010 & 0.024 & 1.033 & -0.016 & 0.032 \\
\hline $1.0-2.0 \mathrm{~Hz}$ & 0.942 & -0.126 & 0.048 & 0.977 & -0.036 & 0.035 & 0.991 & -0.026 & 0.025 & 0.990 & 0.044 & 0.031 \\
\hline $3.0-4.0 \mathrm{~Hz}$ & 0.921 & -0.131 & 0.081 & 0.978 & -0.038 & 0.059 & 0.992 & -0.032 & 0.041 & 0.992 & 0.047 & 0.046 \\
\hline $4.0-5.0 \mathrm{~Hz}$ & 0.941 & -0.162 & 0.074 & 0.997 & -0.057 & 0.054 & 1.005 & -0.045 & 0.037 & 0.979 & 0.063 & 0.041 \\
\hline $7.0-8.0 \mathrm{~Hz}$ & 0.965 & -0.262 & 0.098 & 1.023 & -0.137 & 0.069 & 1.021 & -0.096 & 0.047 & 0.966 & 0.104 & 0.046 \\
\hline $8.0-9.0 \mathrm{~Hz}$ & 0.966 & -0.241 & 0.093 & 1.034 & -0.142 & 0.066 & 1.029 & -0.101 & 0.044 & 0.958 & 0.112 & 0.042 \\
\hline $9.0-10.0 \mathrm{~Hz}$ & 0.962 & -0.224 & 0.094 & 1.024 & -0.107 & 0.070 & 1.021 & -0.076 & 0.047 & 0.968 & 0.086 & 0.047 \\
\hline
\end{tabular}

\begin{tabular}{|c|c|c|c|c|c|c|c|c|c|c|c|c|}
\hline & \multicolumn{3}{|c|}{$\zeta=20 \%$} & \multicolumn{3}{|c|}{$\zeta=30 \%$} & \multicolumn{3}{|c|}{$\zeta=40 \%$} & \multicolumn{3}{|c|}{$\zeta=50 \%$} \\
\hline f.b. & $\mathrm{e}_{\mathrm{i}, 5}$ & $\mathrm{f}_{\mathrm{i}, 5}$ & $\mathrm{~S}_{5}$ & $\mathrm{e}_{\mathrm{i}, 6}$ & $\mathrm{f}_{\mathrm{i}, 6}$ & $\mathrm{~S}_{6}$ & $e_{i, 7}$ & $f_{i, 7}$ & $\mathrm{~S}_{7}$ & $\mathrm{e}_{\mathrm{i}, 8}$ & $\mathrm{f}_{\mathrm{i}, 8}$ & $\mathrm{~S}_{8}$ \\
\hline $0.1-1.0 \mathrm{~Hz}$ & 1.069 & -0.040 & 0.080 & 1.089 & -0.058 & 0.117 & 1.101 & -0.073 & 0.147 & 1.108 & -0.086 & 0.171 \\
\hline $1.0-2.0 \mathrm{~Hz}$ & 0.956 & 0.114 & 0.073 & 0.924 & 0.163 & 0.100 & 0.895 & 0.199 & 0.120 & 0.868 & 0.226 & 0.134 \\
\hline $3.0-4.0 \mathrm{~Hz}$ & 0.963 & 0.115 & 0.098 & 0.931 & 0.162 & 0.126 & 0.900 & 0.198 & 0.142 & 0.871 & 0.227 & 0.153 \\
\hline $4.0-5.0 \mathrm{~Hz}$ & 0.937 & 0.143 & 0.086 & 0.900 & 0.194 & 0.110 & 0.867 & 0.230 & 0.125 & 0.836 & 0.257 & 0.135 \\
\hline $7.0-8.0 \mathrm{~Hz}$ & 0.910 & 0.223 & 0.095 & 0.863 & 0.295 & 0.121 & 0.822 & 0.348 & 0.138 & 0.785 & 0.388 & 0.150 \\
\hline $8.0-9.0 \mathrm{~Hz}$ & 0.895 & 0.245 & 0.087 & 0.845 & 0.329 & 0.114 & 0.802 & 0.391 & 0.133 & 0.764 & 0.441 & 0.147 \\
\hline $9.0-10.0 \mathrm{~Hz}$ & 0.912 & 0.203 & 0.098 & 0.863 & 0.288 & 0.129 & 0.819 & 0.356 & 0.151 & 0.779 & 0.413 & 0.169 \\
\hline
\end{tabular}

\section{APPLICABILITY OF SCF IN PRACTICE}

So far, the concept of the SCF was proposed and relationships between $\sigma$ and SCFs (as well as $\sigma$ and $D C F_{R} \mathrm{~S}$ and $\sigma$ and $D C F_{E} \mathrm{~S}$ ) have been presented. In this chapter, possible practical application of the $S C F$ is discussed. See Fig. 10 for a schematic representation.

According to Nagao and Kanda (2012), $\sigma$ could be estimated from some design presumptions such as scenario earthquake type, magnitude, depth, hypocentral distance $(D)$, the average shear wave 
velocity $(\overline{V s})$ and geological attenuation property $\left(\frac{-\pi^{*} f}{\bar{Q}}\right)$ from source to site. The parameters are used for determining the energy attenuation from source to site, E.A., to approximate $\sigma$ from already proposed $\sigma$-E.A. relationships in some frequency bands. More details can be found in Nagao and Kanda (2012).

From the $\sigma$ values obtained above and the $\sigma-S C F$ relations and $\sigma-D C F_{R}$ relations in this study, values of the $S C F \mathrm{~s}$ and $D C F_{R} S$ can be estimated in the frequency bands. Using both $S C F \mathrm{~s}$ and $D C F_{R} S$ enables to define two different types of design spectra with damping ratios of interest - the pseudo-velocity response spectra $\left(\mathrm{PS}_{\mathrm{v}}\right)$ and energy spectra - from a $5 \%$ damping design acceleration response spectrum in building design codes. Those spectra are denoted as $D S_{v}$ and $D V_{E}$, respectively.

The algorithm proposed in Nagao and Kanda (2014) would make it possible to simulate a causal ground motion compatible to the two types of design spectra. The algorithm has the following twelve steps:

1. Define the $5 \%$ damping design acceleration response spectrum $\left(D S_{a}\right)$ and $\mu$ and $\sigma$ in the ten signal frequency bands.

2. Set the iteration number, $I=1$.

3. Define the design pseudo-velocity response spectrum, $D S_{v}$, by $D S_{a}\left(\omega_{n}\right) / \omega_{n}$, where $\omega_{n}=$ natural circular frequency in rad/s. Further, define the initial Fourier amplitudes, $F_{I}$, by multiplying $D S_{v}$ by $D C F_{R, \zeta=0 \%}$, the damping correction factor for $0 \%$ damping.

The initial Fourier amplitudes are defined in the interval 0.05-30.0 Hz, though $D S_{a}$ and $D S_{v}$ are defined for $0.1-10.0 \mathrm{~Hz}$. (The $D C F_{R, \zeta=0 \%}$ outside $0.1-10.0 \mathrm{~Hz}$ was estimated by linear extrapolation, whereas $D S_{v}$ outside $0.1-10.0 \mathrm{~Hz}$ was approximated directly using the equation defining $D S_{a}$ in Japan's code.) It is because response of a structure having a natural frequency, $10.0 \mathrm{~Hz}$, for instance, should be influenced not only by the signal frequency component at $10.0 \mathrm{~Hz}$ but also by the signal components at surrounding frequencies. To consider this, the Fourier amplitudes were defined in a broader frequency range than $0.1-10.0 \mathrm{~Hz}$.

4. Generate normal random variables having $\mu$ and $\sigma$ in each of the ten frequency bands. The normal random variables are an initial set of phase difference $\left(\Delta \phi_{I, k}, k=16,17, \ldots, 1639\right)$. Note that for $N=$ 32768 and $\Delta t=0.005 \mathrm{~s}, \Delta \phi_{I, 16}$ is the phase difference at about $0.1 \mathrm{~Hz}$ and $\Delta \phi_{I, 1639}$ is phase difference at about $10.0 \mathrm{~Hz}$. In step 3, Fourier amplitudes are defined also in the ranges $0.05-0.1 \mathrm{~Hz}$ and $10.0-30.0 \mathrm{~Hz}$. The $\mu$ and $\sigma$ values for $0.1-1.0 \mathrm{~Hz}$ and $9.0-10.0 \mathrm{~Hz}$ are used to generate the initial phase differences for $0.05-0.1 \mathrm{~Hz}$ and $10.0-30.0 \mathrm{~Hz}$, respectively. For phase difference data at other frequencies, random variables ranging from $-2 \pi$ to $0 \mathrm{rad}$ are used.

5. Compute the phase angles $\phi_{I, k}(k=1,2, \ldots, \mathrm{N} / 2-1)$ from the phase differences $\Delta \phi_{I, k}$ using Eq. (2.a).

6. Take the inverse Fourier transform and generate the ground motion $X_{I, m}(m=1,2, \ldots, 32768)$.

7. Compute the $5 \%$ damping velocity response spectrum (denoted $S_{v, I}$ ) and spectral ratio, a function of frequency, as follows:

$$
\begin{gathered}
R S_{I, k}=\frac{D S_{v, k}}{S_{v, I, k}} \quad(k=16,17, \ldots, 1639) \\
R S_{I, k}=1 \quad \text { (elsewhere) }
\end{gathered}
$$

8. Multiply $F_{I}$ by $R S_{I}$ to obtain $F_{I}^{\prime}$.

$$
F_{I, k}^{\prime}=F_{I, k} * R S_{I, k}(k=1,2, \ldots, \mathrm{N} / 2+1)
$$


9. Compute the real part $A_{I, k}(k=1,2, \ldots, \mathrm{N} / 2+1)$ as follows:

$$
A_{I, k}=F_{I, k}^{\prime} * \cos \left(\phi_{I, k}\right)
$$

Then take the Hilbert transform of the real part $A_{I, k}$ to obtain $B_{I, k}{ }^{*}(k=1,2, \ldots, \mathrm{N} / 2+1)$.

10. Update the Fourier amplitudes by

$$
F_{I+1, k}=\sqrt{A_{I, k}^{2}+B_{I, k}^{* 2}}
$$

Then, compute the phase differences by using $A_{I, k}, B_{I, k}{ }^{*}$, and Eq. (2). The phase differences are denoted $\Delta \phi_{I}$.

11. Compute the statistical values of $\Delta \phi_{I}^{\prime}$ in each frequency band to check whether the $\Delta \phi I^{\prime}$ have mean and standard deviation values which are close to those specified in step 1 . Usually, the standard deviation values of the $\Delta \phi \dot{I}$ are smaller than the design values specified in step 1 at the first iteration, while the mean values are almost equal. To correct the standard deviation values, the following adjustment is done. For each of the $\Delta \phi_{I}^{\prime}$ values in a frequency band,

$$
\begin{aligned}
\left(\Delta \phi_{I+1}\right)_{i \text { th } f . b .} & =\operatorname{mean}\left[\left(\Delta_{I}^{\prime}\right)_{i \text { th } f . b .}\right] \\
& +\left[\left(\Delta \phi_{I}^{\prime}\right)_{i \text { th } f . b .}-\operatorname{mean}\left[\left(\Delta_{I}^{\prime}\right)_{i \text { th } f . b .}\right]\right] * R_{i \text { th } f . b .}
\end{aligned}
$$

Where

$$
R_{\text {ith } f . b .}=\frac{\sigma_{i \text { th } f . b .}}{\text { standard deviation }\left[\left(\Delta \phi_{I}^{\prime}\right)_{i \text { th } f . b .}\right]}
$$

By Eq. (15), each $\Delta \phi I^{\prime}$ value is corrected so that the variance of $\Delta \phi^{\prime}$ in the frequency band becomes the same value as $\sigma^{2}$. As for the mean values, the following adjustment is done:

$$
\left(\Delta \phi_{I+1}\right)_{i \text { th } f . b .}=\left(\Delta \phi_{I+1}\right)_{i \text { th } f . b .}+\left(\mu_{i \text { th } f . b .}-\operatorname{mean}\left[\left(\Delta_{\phi_{I+1}}\right)_{i \text { th } f . b .}\right]\right)
$$

Due to this adjustment, the intended $\mu$ and $\sigma$ values can be obtained in all frequency bands.

12. Set $I=I+1$ and go back to step 5 . The iteration continues until the difference between unity and mean value of $R S_{I}$ in Eq. (11.a) becomes less than a certain small value. In this study, the value used was $2 \%$. In many cases, this requirement can be satisfied in less than 5-time-iterations.

Three numerical examples are given. The first example is an interplate earthquake, the second is a 
crustal earthquake, and the third is an intraplate earthquake. For each example, all assumptions are listed in Table 6. Further, Table 7 gives all approximated $\mu$ and $\sigma$. The $\mu$ values were determined so that the difference of $\mu$ for two neighbouring frequency bands equals to difference of $\sigma$ for the same two neighbouring frequency bands. Note however that frequency bands having larger $\sigma$ value have smaller $\mu$ value. See Nagao (2012) for details. In this process, the value of $\mu$ in the first frequency band (e.g. $0.1-1.0 \mathrm{~Hz}$ ) has to be assumed. The $\mu$ in $0.1-1.0 \mathrm{~Hz}$ should be greater than -1.570 rad to simulate causal ground motions. From the values of $\sigma$ in Table $7, D C F_{R}$ s were calculated and multiplied by the Japan's 5\% damping design acceleration response spectrum to yield $\zeta \%$ damping acceleration response spectrum. In this study, $1 \%$ and $10 \%$ damping ratio cases were considered. From the design acceleration response spectra, the pseudo-velocity spectra were estimated. Moreover, by using the results of SCFs in this research, expected energy spectra were determined in each case. Finally, by applying the algorithm, a causal ground motion compatible to the $5 \%$ damping pseudo-velocity response spectrum was generated for each case. See Fig. 11, Fig. 12 and Fig. 13 for case1, case2, and case3, respectively. Each of the three figures contains the generated time history, its velocity response spectra together with the estimated design pseudo-velocity response spectra, and its energy spectra along with the estimated design energy spectra.

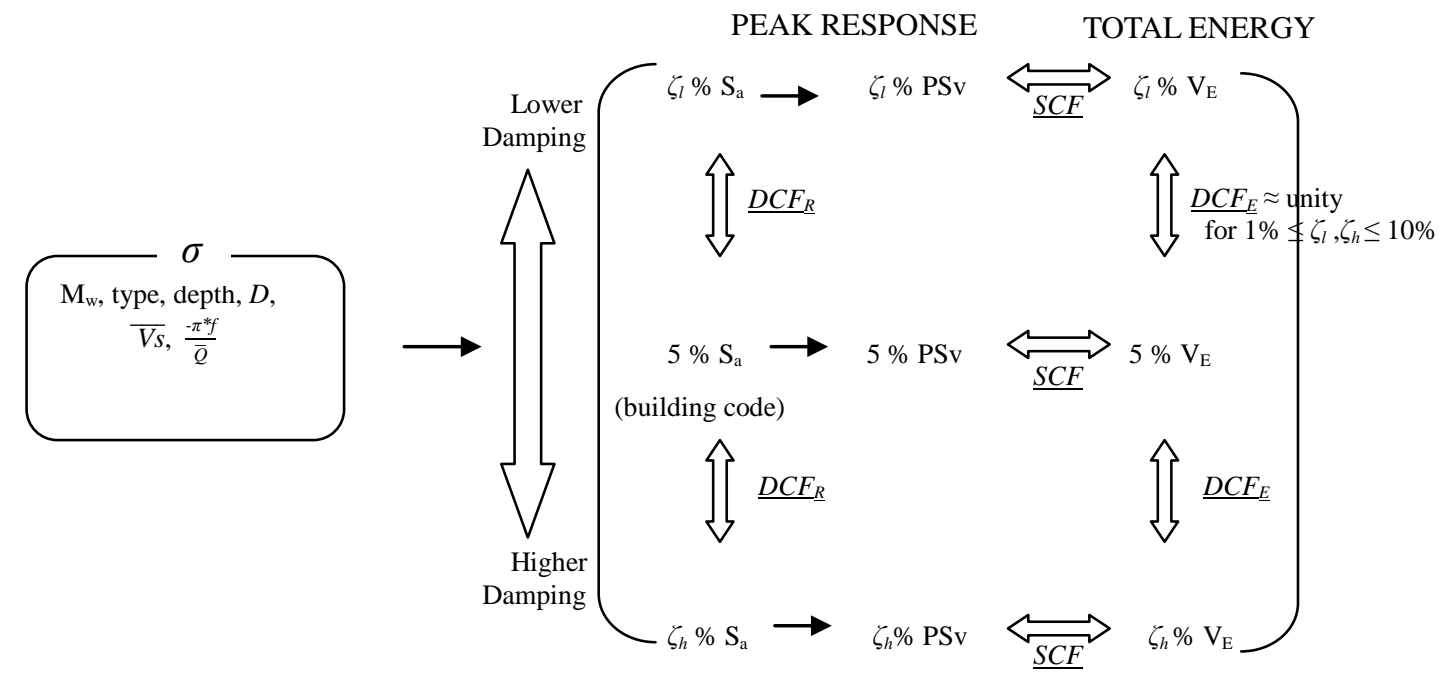

Fig. 10 Schematic representation for application of SCF, $\mathrm{DCF}_{\mathrm{E}}$, and $\mathrm{DCF}_{\mathrm{R}}$

Table 6 Assumptions in the examples

\begin{tabular}{|c|c|c|c|c|c|c|}
\hline Case \# & Type & $\mathrm{M}_{\mathrm{w}}$ & $\mathrm{D}(\mathrm{km})$ & Depth $(\mathrm{km})$ & $\overline{\mathrm{Vs}}(\mathrm{km} / \mathrm{s})$ & $\frac{-\pi^{*} \mathrm{f}}{\overline{\mathrm{Q}}}$ \\
\hline 1 & Interplate & 7.9 & 130 & 45 & 3.5 & -0.01245 in all f.b. \\
\hline 2 & Crustal & 6.6 & 30 & 10 & 3.0 & -0.06227 in all f.b. \\
\hline 3 & Intraplate & 6.7 & 80 & 55 & 3.5 & -0.03737 in all f.b. \\
\hline
\end{tabular}

Table 7 Estimated means and standard deviations of phase difference for each case

\begin{tabular}{|c|c|c|c|c|c|c|}
\hline & \multicolumn{2}{|c|}{ Case1 } & \multicolumn{2}{c|}{ Case2 } & \multicolumn{2}{c|}{ Case3 } \\
\hline f.b. & $\mu$ (radian) & $\sigma$ (radian) & $\mu$ (radian) & $\sigma$ (radian) & $\mu$ (radian) & $\sigma$ (radian) \\
\hline $0.1-1.0 \mathrm{~Hz}$ & -1.570 & 0.640 & -1.000 & 0.323 & -1.200 & 0.371 \\
\hline $1.0-2.0 \mathrm{~Hz}$ & -1.346 & 0.416 & -0.907 & 0.230 & -1.143 & 0.314 \\
\hline $2.0-3.0 \mathrm{~Hz}$ & -1.122 & 0.192 & -0.872 & 0.195 & -1.079 & 0.250 \\
\hline $3.0-4.0 \mathrm{~Hz}$ & -1.148 & 0.218 & -0.863 & 0.186 & -1.041 & 0.212 \\
\hline $4.0-5.0 \mathrm{~Hz}$ & -1.166 & 0.236 & -0.869 & 0.192 & -1.02 & 0.191 \\
\hline $5.0-6.0 \mathrm{~Hz}$ & -1.167 & 0.237 & -0.888 & 0.211 & -1.016 & 0.187 \\
\hline $6.0-7.0 \mathrm{~Hz}$ & -1.159 & 0.229 & -0.907 & 0.230 & -1.012 & 0.183 \\
\hline $7.0-8.0 \mathrm{~Hz}$ & -1.150 & 0.220 & -0.926 & 0.249 & -1.008 & 0.179 \\
\hline $8.0-9.0 \mathrm{~Hz}$ & -1.141 & 0.211 & -0.945 & 0.268 & -1.004 & 0.175 \\
\hline $9.0-10.0 \mathrm{~Hz}$ & -1.133 & 0.203 & -0.964 & 0.287 & -1.000 & 0.171 \\
\hline
\end{tabular}


To quantitatively evaluate how well each of the ground motions is compatible to the expected design spectra, following quantities were defined.

$$
\begin{aligned}
& A V_{R}=\text { mean }\left(\frac{S_{V, \zeta=1 \%}}{D S_{V, \zeta=1 \%}}\right){ }_{0.1-10.0 \mathrm{~Hz}} \\
& A V_{E}=\operatorname{mean}\left(\frac{V_{E, \zeta=10 \%}}{D V_{E, \zeta=10 \%}}\right)_{0.1-10.0 \mathrm{~Hz}}
\end{aligned}
$$

where $S_{v, \zeta=1 \%}$ is the $1 \%$ damping velocity response spectrum of a simulated causal ground motion, $D S_{V, \zeta=1 \%}$ is the estimated 1\% damping design pseudo-velocity response spectrum, $V_{E, \zeta=10 \%}$ is the $10 \%$ damping energy spectrum of a simulated causal ground motion, and $D V_{E, \zeta=10 \%}$ is the estimated $10 \%$ damping design energy spectrum. Those quantities obtained are listed from the $2^{\text {nd }}$ to the $3^{\text {rd }}$ column in Table 8. Generally, closer the quantities are to unity, better the compatibilities are. The simulated causal ground motions all have values fairly close to unity. To make a comparison, a ground motion having the same $\mu$ and $\sigma$ in the ten frequency bands and the same 5\% damping pseudo-velocity response spectrum was generated without using the algorithm in each case (i.e. the simulated ground motions are not causal function). Then the quantities $A V_{R}$ and $A V_{E}$ were calculated and listed from the $4^{\text {th }}$ to the $5^{\text {th }}$ column in Table 8 . It should be noted that ground motions using the algorithm give better results in terms of the $A V_{E}$ values, compatibilities with the design energy spectra.

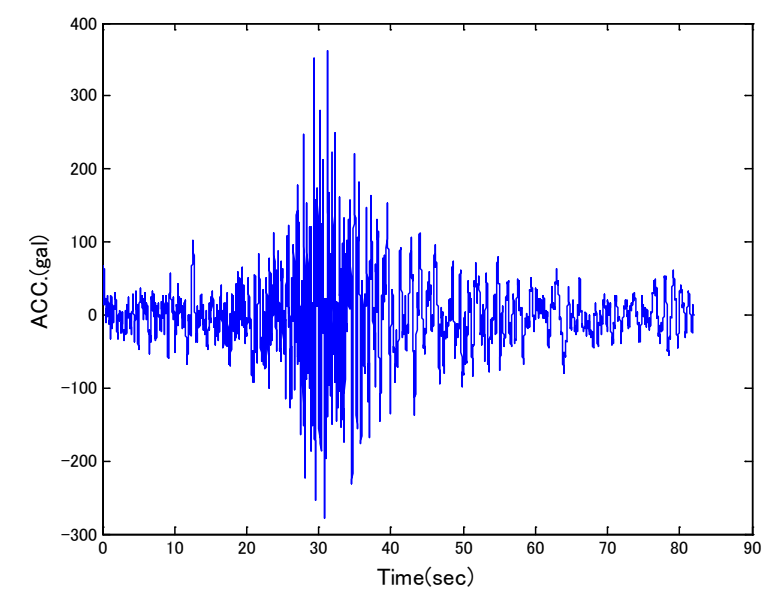

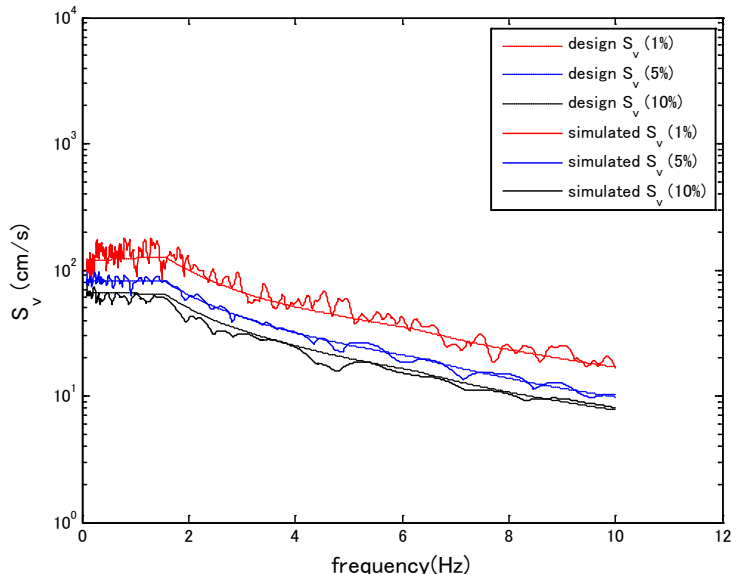

b)

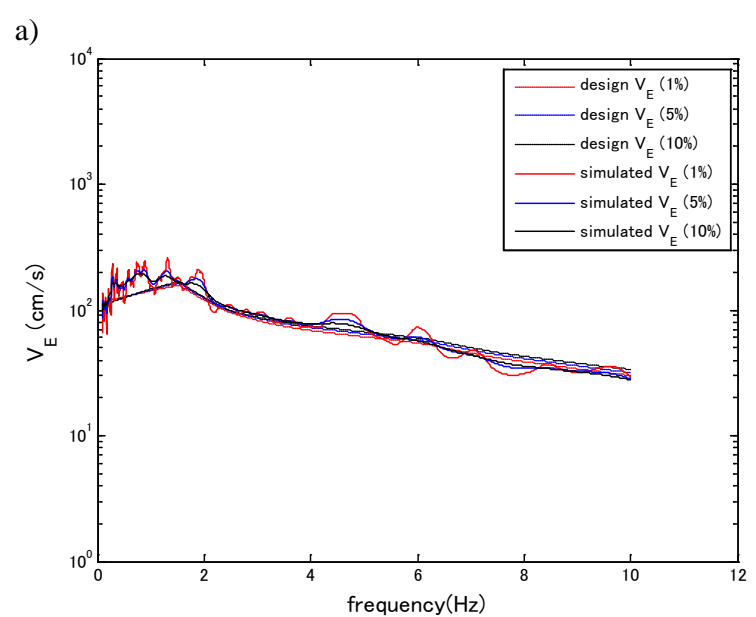

c)

Fig.11 a) simulated ground motion, b) simulated and target design pseudo-velocity response spectra, and c) simulated and target design energy spectra in cases of $1 \%, 5 \%$, and $10 \%$ damping for case 1 


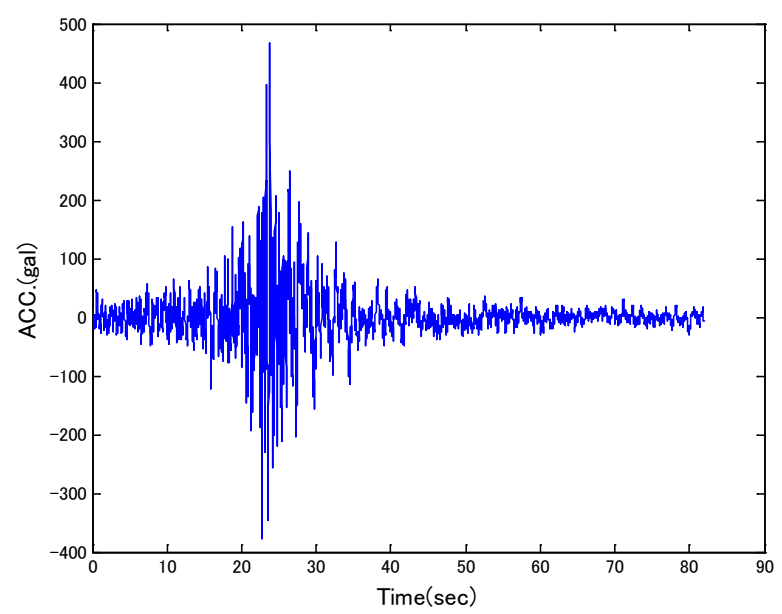

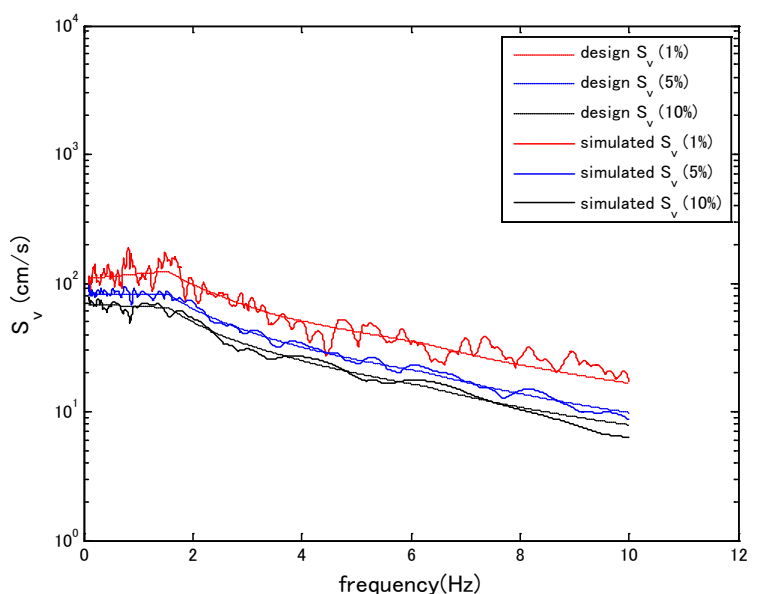

b)

a)

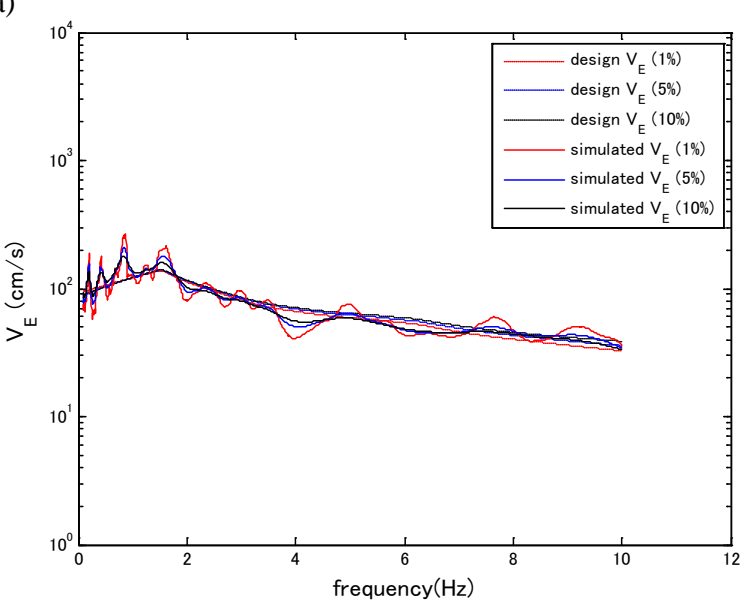

c)

Fig.12 a) simulated ground motion, b) simulated and target design pseudo-velocity response spectra, and c) simulated and target design energy spectra in cases of 1\%, 5\%, and 10\% damping for case 2

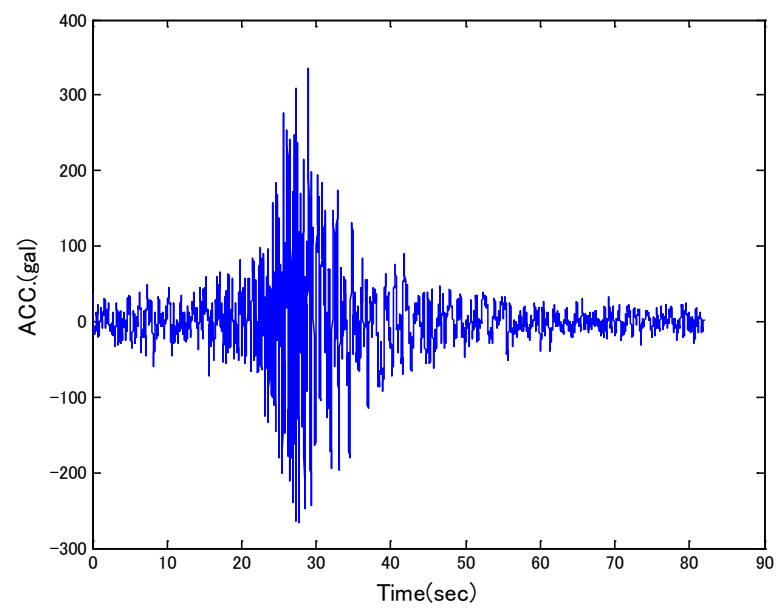

a)

Fig. 13 a) simulated ground motion, b) simulated and target design pseudo-velocity response spectra, and c) simulated and target design energy spectra in cases of 1\%,5\%, and 10\% damping for case 3 
Fig.13 continued

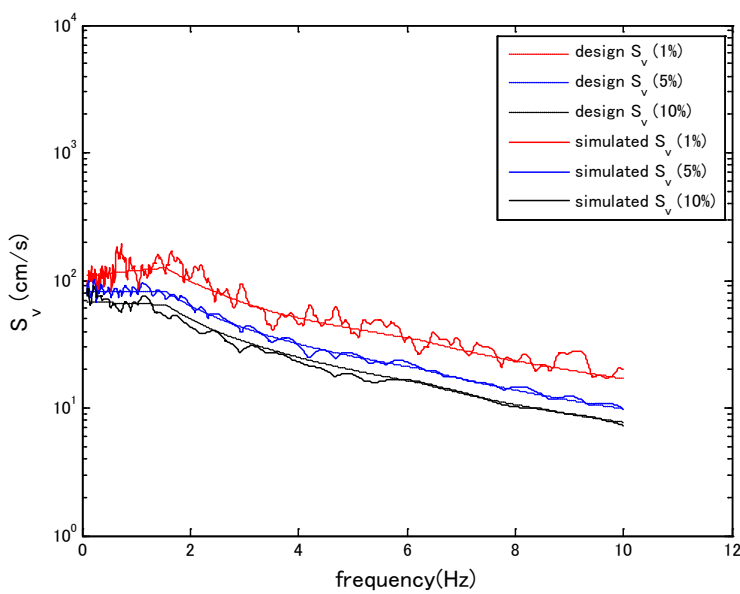

b)

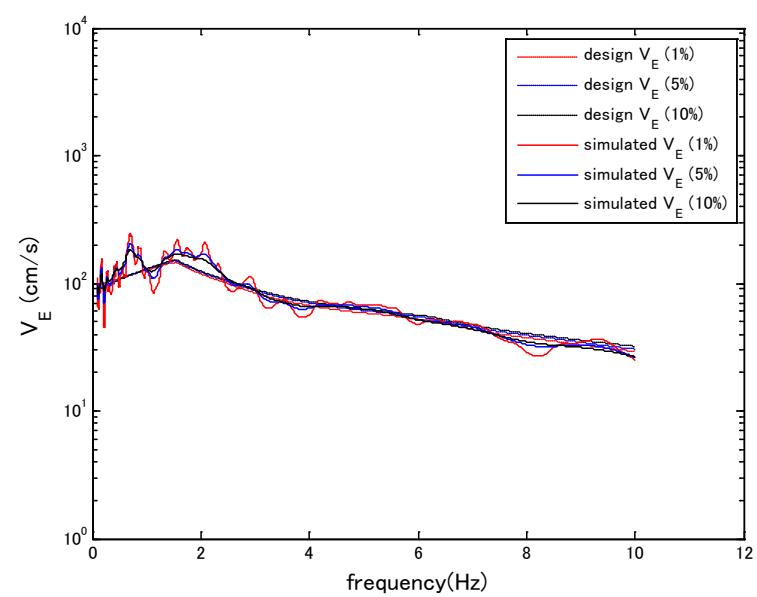

c)

Table 8 Computed $\mathrm{AV}_{\mathrm{R}}$ and $\mathrm{AV}_{\mathrm{E}}$ values in each simulation case

\begin{tabular}{|c|c|c|c|c|}
\hline case & $\mathrm{AV}_{\mathrm{R}}$ & $\mathrm{AV}_{\mathrm{E}}$ & $\mathrm{AV}_{\mathrm{R}}$ & $\mathrm{AV}_{\mathrm{E}}$ \\
\hline 1 & 1.086 & 1.029 & 1.023 & 0.865 \\
\hline 2 & 1.060 & 0.974 & 0.986 & 0.782 \\
\hline 3 & 1.082 & 1.003 & 1.044 & 0.853 \\
\hline
\end{tabular}

\section{CONCLUSIONS}

The concept of the Spectrum Conversion Factor was introduced, and relationships between the standard deviations of phase difference and Spectrum Conversion Factors were investigated in ten frequency bands and with nine damping ratios. Although there were no clear tendencies in case of no-damping, high positive correlations were observed with damping. Generally, estimated slope and intercept become larger as frequency or damping ratio becomes larger. In the final part of this research, applicability of the Spectrum Conversion Factors was demonstrated by showing three numerical examples. The simulated causal ground motions have velocity response spectra and energy spectra which are close to the respective design spectra.

\section{SOFTWARE}

Software (coded in Fortran77) used in this study to compute the mean and standard deviation values of phase difference and to compute SCF can be provided with researchers and students (academic use only). If interested, send an email to "nagaok@daiwahouse.jp”. However, the authors do not owe responsibilities to any troubles when using the software.

\section{AKCNOWLEDGEMENT}

The authors utilized KiK-net ground motion data recorded by the National Research Institute for Earth Science and Disaster Prevention, Japan. In addition, the authors greatly acknowledge helpful comments provided by Prof. Toshio Adachi, Nihon University, Japan, and anonymous reviewers. The 
one of the authors also thanks great helps by Koji Nagao, Tokyo Institute of Technology.

\section{REFERENCES}

Akiyama, H. (1985). Earthquake-resistant limit-state design for buildings, $2^{\text {nd }}$ edition. University of Tokyo press, University of Tokyo, Japan.

Akiyama, H. (1999). Earthquake-Resistant Design for Buildings Based on Energy Balance, $1^{\text {st }}$ edition, Gihoudou Publishing Co., Tokyo, Japan (in Japanese).

Akiyama, H. and Kitamura, H. (2006). "Relationship between energy spectra and velocity response spectra.” Journal of Structural and Construction Engineering, Vol.608, 37-43 (in Japanese).

Biot, M. A. (1933). "Theory of elastic systems under transient loading with an application to earthquake proof buildings.” Proceedings, National Academy of Sciences, Vol.19, 262-268.

Housner, G. W. (1941). "Calculating the response of an oscillator to arbitrary ground motion." Bulletin of the Seismological Society of America, vol31, 143-149.

Housner, G. W. (1956). "Limit design of structures to resist earthquakes.” Proceeding of $1^{\text {st }}$ World Conference on Earthquake Engineering, 1-13.

Housner, G. W. (1959). "Behavior of structures during earthquakes.” ASCE EM, Vol.4, 109-129.

Iwasaki, R., Kanda, J., Masao, T., and Ohkawa, I. (1988) "Fundamental properties of phase difference distribution for earthquake ground motions.” Journal of Architectural Institute of Japan Vol.386, 16-23 (in Japanese).

Kato, B. and Akiyama, H. (1975). "Energy input and damages in structures subjected to severe earthquakes.” Journal of Architectural Institute of Japan, Vol.235, 9-18 (in Japanese).

Miyake, T. (2006). "A study on the relationship between maximum response and cumulative response for seismic design.” Journal of Structural and Construction Engineering, Vol.599, 135-142 (in Japanese).

Nagao K. (2012). Study on generation of the design artificial ground motion based on statistical values of phase difference including higher moment, Master's thesis, University of Tokyo (in Japanese).

Nagao, K., and Kanda, J. (2012). "Study on the relationship between standard deviation of phase difference and frequency dependent energy attenuation in Japan.” Proceeding of $15^{\text {th }}$ World Conference on Earthquake Engineering, Paper No.3438.

Nagao, K., and Kanda, J. (2013) "Estimation of damping correlation factors using standard deviation of phase difference.” Earthquake Spectra 2013, published online in December 2013.

Nagao, K., and Kanda, J. (2014) "Study of a ground-motion simulation method using a causal relationship." Journal of Earthquake Engineering 2014, in press.

Ohsaki, Y. (1979). "Study On the significance of phase content in earthquake ground motions." Earthquake Engineering and Structural Dynamics, 7:5, 427-439.

Okano, H., Nagano, M., Imamura, A., Tokumitsu, R., and Hijikata, K. (2009). "Scaling equation between response spectrum and energy spectrum.” Journal of Structural and Construction Engineering, Vol.79, 477 - 486 (in Japanese).

Papoulis, A. (1977). Signal Analysis, McGraw-Hill Co., NY.

Yamane, T., and Nagahashi, S. (2002). "A study on a generation of simulated earthquake ground motion considering phase difference characteristics: Part 1 Theoretical background of the relationship between phase difference distribution and envelope”. Journal of Structural and Construction Engineering, Vol.553, 49-56 (in Japanese). 